Acta Crystallographica Section D

\section{Biological Crystallography}

ISSN 1399-0047

\section{Adele Williamson, ${ }^{\mathrm{a} *}$ Ulli Rothweiler $^{b}$ and Hanna-Kirsti Schrøder Leiros ${ }^{b}$}

a Department of Chemistry, UiT The Arctic University of Norway, N-9037 Tromsø, Norway, and ${ }^{\mathbf{b}}$ NorStruct, Department of Chemistry, UiT The Arctic University of Norway, N-9037 Tromsø, Norway

Correspondence e-mail: adele.k.williamson@uit.no

\title{
Enzyme-adenylate structure of a bacterial ATP-dependent DNA ligase with a minimized DNA-binding surface
}

DNA ligases are a structurally diverse class of enzymes which share a common catalytic core and seal breaks in the phosphodiester backbone of double-stranded DNA via an adenylated intermediate. Here, the structure and activity of a recombinantly produced ATP-dependent DNA ligase from the bacterium Psychromonas sp. strain SP041 is described. This minimal-type ligase, like its close homologues, is able to ligate singly nicked double-stranded DNA with high efficiency and to join cohesive-ended and blunt-ended substrates to a more limited extent. The $1.65 \AA$ resolution crystal structure of the enzyme-adenylate complex reveals no unstructured loops or segments, and suggests that this enzyme binds the DNA without requiring full encirclement of the DNA duplex. This is in contrast to previously characterized minimal DNA ligases from viruses, which use flexible loop regions for DNA interaction. The Psychromonas sp. enzyme is the first structure available for the minimal type of bacterial DNA ligases and is the smallest DNA ligase to be crystallized to date.

\section{Introduction}

The sealing of breaks in the phosphodiester backbone of double-stranded DNA is essential for the replication and survival of all organisms. This function is carried out by DNA ligases in a three-step reaction in which the enzyme first selfadenylates, followed by DNA binding and transfer of AMP to the $5^{\prime}$-phosphate terminus of the DNA nick, which is then activated for nucleophilic attack by the apposing $3^{\prime}-\mathrm{OH}$ group. This final step creates a new phosphodiester bond and releases the AMP.

DNA ligases are members of the nucleotidyltransferase superfamily and are similar to the GTP-dependent mRNAcapping enzymes (Shuman \& Lima, 2004). The nature of the AMP donor for DNA ligases divides them into two classes: the highly conserved NAD-dependent enzymes, which are found in all bacteria and carry out the essential joining of Okazaki fragments during DNA replication (Wilkinson et al., 2001), and the structurally diverse ATP-dependent enzymes, which are found in all domains of life (Martin \& MacNeill, 2002). This division in cofactor preference is reflected in distinct structural differences, with NAD-dependent DNA ligases possessing a unique $\mathrm{N}$-terminal Ia domain which is essential for utilization of this substrate (Sriskanda \& Shuman, 2002). ATP-dependent DNA ligases (abbreviated ADLs) share a common catalytic core which includes all six of the conserved nucleotidyltransferase motifs and comprises the adenylation domain (AD domain), where the AMP cofactor is covalently bound, and an oligonucleotide-binding domain (OB domain),
Received 15 July 2014

Accepted 22 September 2014

PDB reference:

ATP-dependent DNA ligase, $4 \mathrm{~d} 05$ 
which engages the minor groove of the DNA duplex upon nick binding and assists in the step 1 adenylation reaction (Shuman, 2009; Doherty \& Suh, 2000). These two essential domains are appended with a variety of organism-specific domains and motifs which are involved in DNA binding (Pascal et al., 2004; Nair et al., 2007), cellular localization (Lakshmipathy \& Campbell, 1999) or the recruitment of other protein interaction partners (Pascal et al., 2006; Liu et al., 2013; Kiyonari et al., 2006), or in some cases have independent enzymatic functions (Zhu et al., 2006; Zhu \& Shuman, 2005, 2006).

Enzyme-substrate intermediates in the ligation reaction have been crystallized for a number of ADLs, including several ligase-adenylate structures (Kiyonari et al., 2006; Subramanya et al., 1996; Odell et al., 2000; Nishida et al., 2005; Akey et al., 2006) and three with nicked DNA bound in the active site: the small Chlorella virus PBCV-1 DNA ligase (hereafter referred to as ChlV-Lig; Nair et al., 2007) and the two large eukaryotic human DNA ligases I and III (Pascal et al., 2004; Cotner-Gohara et al., 2010). Comparison of the DNA-bound and DNA-free forms of these proteins indicate that their substrate-binding mode is mechanistically conserved, with the enzyme fully encircling the DNA strand, but that different protein structures are used to accomplish this. In both cases the protein transitions from an open conformation in which the DNA-binding sites of the AD and OB domains are oriented away from each other to a closed conformation by rotation of the two domains about their flexible linker section (Shuman, 2009). In ChlV-Lig the ring structure around the DNA is completed by ordering of a large loop region that protrudes from the $\mathrm{OB}$ domain and wraps around the strand to form contacts with the $\mathrm{AD}$ domain, while in ligases I and III encirclement involves a large N-terminal DNA-binding domain comprising $12 \alpha$-helices.

All bacterial genomes encode an essential NAD-dependent DNA ligase which joins Okazaki fragments during DNA replication, but some species also have additional ATPdependent proteins (Wilkinson et al., 2001). Bacterial ADLs appear to fall into two broad categories: large intracellular enzymes that are involved in double-stranded break repair (Pitcher et al., 2007) and smaller proteins, many of which possess a predicted periplasmic leader peptide. The first group, typified by the LigD ADLs from Bacillus subtillis and Mycobacterium tuberculosis, require the DNA end-binding protein $\mathrm{Ku}$ for optimal activity (Weller et al., 2002; Della et al., 2004) and in many cases are multi-functional with additional DNArepair activities imparted by enzymatic domains in the same polypeptide chain (Zhu \& Shuman, 2005, 2006; Zhu et al., 2005, 2006, 2012; Wright et al., 2010). To date, the only structure of a bacterial ADL that has been determined is that of the large multi-functional M. tuberculosis LigD protein (hereafter referred to as Mtu-Lig), the C-terminal ligase domain of which (residues 452-759) was crystallized in an adenylated form (Akey et al., 2006), while the X-ray structure of the primase/polymerase domain was determined separately (Zhu et al., 2006). The second type of bacterial ADLs, which are found predominantly in the Proteobacteria, only have the minimal core architecture and show high rates of intrinsic nick-sealing activity (Cheng \& Shuman, 1997; Magnet \& Blanchard, 2004). Two such 'minimal' ADLs from the human pathogens Neisseria meningitidis (hereafter referred to as Nme-Lig; Magnet \& Blanchard, 2004) and Haemophilus influenzae (hereafter referred to as Hin-Lig; Cheng \& Shuman, 1997) have been recombinantly produced and their enzymatic activities have been extensively characterized. Both are capable of sealing single-nicked double-stranded DNA (ds-DNA) without requiring additional protein-interaction partners and both have relatively high affinity for both ATP and DNA substrates. Recently, preliminary characterization of recombinant ADL from the psychrophilic fish pathogen Aliivibrio salmonicida (hereafter referred to as Vib-Lig) showed increased rates of nick sealing when the protein did not include the $\mathrm{N}$-terminal leader sequence, which provides strong support for the periplasmic location of these enzymes in the native host (Williamson \& Pedersen, 2014).

Here, we report the biochemical and structural characterization of a bacterial ADL present in the partially sequenced genome of the psychrotolerant Psychromonas sp. strain SP041 isolated from Svalbard, Norway. This protein, hereafter referred to as Psy-Lig, is a minimal type of bacterial ADL possessing only the catalytic domains necessary for selfadenylation and nick-sealing and an $\mathrm{N}$-terminal periplasmic localization sequence. The $1.65 \AA$ resolution structure of the enzyme-adenylate complex presented here represents only the second structure of a bacterial ADL to date and is the only available structure of the minimal type of bacterial ADL. At 257 residues, it is also the smallest DNA ligase that has been structurally studied, being 41 residues shorter than the minimal ChlV-Lig protein, and comparison with this homologue suggests that it may use an alternative mode of engaging its DNA substrate to those previously described.

\section{Experimental procedures}

\subsection{Cloning and expression of Psy-Lig}

Psy-Lig was identified at positions 201749-202642 (reverse strand) in the genome of Psychromonas sp. strain SP041 (GenBank accession No. ERP003516) using Glimmer3 for gene prediction (Delcher et al., 2007) and homology searches against the nonredundant protein sequences database. SignalP 4.1 (Gram-negatives networks setting, $D$ cutoff value 4.2; Petersen et al., 2011) predicted a periplasmic targeting leader sequence of 40 amino acids with a cleavage position between residues Ala40 and Gln41. A codon-optimized synthetic DNA construct (Eurofins) encoding the mature protein along with an N-terminal His tag and TEV protease site was inserted into the entry vector pDONR22 and then subsequently cloned into and expressed from the Gateway destination vector PHMGWA (GenBank number EU680841). All cloning, expression and purification steps were carried out as described previously for the homologous protein from $A$. salmonicida (Williamson \& Pedersen, 2014). The clarified lysate was incubated overnight with $0.1 \mathrm{~m} M$ ATP to ensure complete adenylation of the purified enzyme. 
Table 1

MAD data-collection, reduction and refinement statistics for Psy-Lig (PDB entry 4d05).

\begin{tabular}{|c|c|c|c|c|}
\hline & High-resolution SeMet & Peak & Inflection point & Remote \\
\hline \multicolumn{5}{|l|}{ Data-collection statistics } \\
\hline Beamline & BL14.1, BESSY & \multicolumn{3}{|c|}{ BL14.1, BESSY } \\
\hline Space group & $C 2$ & \multicolumn{3}{|l|}{$C 2$} \\
\hline Unit-cell parameters $\left(\AA{ }^{\circ}{ }^{\circ}\right)$ & $\begin{array}{l}a=178.43, b=43.98 \\
\quad c=89.63, \gamma=105.92\end{array}$ & \multicolumn{3}{|c|}{$a=178.55, b=43.92, c=89.13, \gamma=105.95$} \\
\hline Wavelength & 0.918409 & 0.979771 & 0.979927 & 0.977455 \\
\hline Energy (keV) & & 12.654 & 12.652 & 12.684 \\
\hline$f^{\prime \prime} / f^{\prime}$ (observed) $\left(\mathrm{e}^{-}\right)$ & & $0.5 /-8.06$ & $0.5 /-7.0$ & $3.8 /-5.4$ \\
\hline Total rotation range $\left({ }^{\circ}\right)$ & 300 & 720 & 360 & 360 \\
\hline Resolution $(\AA)$ & $44-1.65(1.74-1.65)$ & $\begin{array}{l}44-2.73 \\
\quad(2.88-2.73)\end{array}$ & $\begin{array}{l}44-2.89 \\
\quad(3.05-2.89)\end{array}$ & $\begin{array}{l}44-2.84 \\
\quad(3.00-2.84)\end{array}$ \\
\hline No. of unique reflections & 80785 (11590) & $17901(2389)$ & $15206(2134)$ & $16011(2232)$ \\
\hline$R_{\text {merge }}(\%)$ & $7.3(60.1)$ & $25.3(78.4)$ & $20.2(57.6)$ & $19.3(57.3)$ \\
\hline Mean $I / \sigma(I)$ & $13.3(2.1)$ & $9.6(3.0)$ & $8.2(3.0)$ & $9.2(3.0)$ \\
\hline Completeness (\%) & $99.6(98.8)$ & $98.8(91.9)$ & $99.6(97.2)$ & $99.4(96.0)$ \\
\hline Multiplicity & $4.5(4.3)$ & $13.2(11.8)$ & $6.7(6.8)$ & $6.7(6.8)$ \\
\hline \multicolumn{5}{|l|}{ MAD phasing } \\
\hline Resolution $(\AA)$ & & $25-3.2$ & & \\
\hline No. of Se sites & & 13 & & \\
\hline FOM (after SHELXE) & & $0.726[1.65 \AA]$ & & \\
\hline $\begin{array}{l}\text { Pseudo-free CC } \\
\quad \text { after } S H E L X E(\%)\end{array}$ & & $75.6[1.65 \AA]$ & & \\
\hline \multicolumn{5}{|l|}{ Refinement } \\
\hline Resolution range $(\AA)$ & $25-1.65$ & & & \\
\hline$R / R_{\text {free }}(\%)$ & $14.54 / 19.24$ & & & \\
\hline \multicolumn{5}{|l|}{$B$ factor $\left(\AA^{2}\right)$} \\
\hline Protein (chains $A / B$ ) & $11.6 / 32.8$ & & & \\
\hline Water & 28.0 & & & \\
\hline AMP & 15.4 & & & \\
\hline $\mathrm{Mg}$ & 41.4 & & & \\
\hline Sulfate & 35.0 & & & \\
\hline R.m.s. deviation, bonds $(\AA)$ & 0.013 & & & \\
\hline R.m.s. deviation, angles $\left({ }^{\circ}\right)$ & 1.439 & & & \\
\hline \multicolumn{5}{|l|}{ Ramachandran plot } \\
\hline Favoured (\%) & 96.9 & & & \\
\hline Allowed (\%) & 3.1 & & & \\
\hline Disallowed (\%) & 0 & & & \\
\hline
\end{tabular}

Prior to the commencement of crystallization trials, fresh SeMet-substituted Psy-Lig protein was concentrated to $8.0 \mathrm{mg} \mathrm{ml}^{-1}$. The protein was crystallized using the hanging-drop vapourdiffusion method at $4{ }^{\circ} \mathrm{C}$ from $0.1 \mathrm{M}$ HEPES pH 7.4, 1.6-1.9 $M$ ammonium sulfate as a precipitant. Crystals appeared after 2 days and reached maximum size in approximately one week. All crystals were cryoprotected using 1.4 $M$ ammonium sulfate, $0.1 \mathrm{M}$ HEPES pH 7.5, 27\% ethylene glycol and were flash-cooled in liquid nitrogen. Data were collected at the BESSY II synchrotron, Berlin, Germany.

To obtain the phases, a MAD experiment was performed on SeMetlabelled Psy-Lig crystallized from 1.9 $\mathrm{M}$ ammonium sulfate. Anomalous data were collected to $2.9 \AA$ resolution based on a fluorescence scan of the selenium at peak, inflection and remote energies $(12.6545, \quad 12.6525$ and $12.6845 \mathrm{keV}$, respectively). A subsequent highresolution data set was collected from a second SeMet crystal crystallized using $1.75 \mathrm{M}$ ammonium sulfate, which diffracted to $1.65 \AA$ A resolution (Table 1).

2.2.2. Structure determination and refinement. A substructure of $13 \mathrm{Se}$ sites was found in SHELXD with occupancies of 1.0-0.5 using the three-

Production of SeMet-substituted Psy-Lig was performed by cultivation of Escherichia coli BL21(DE3)Star PlysS/ PHMGWA:: psy-Lig cells in M9 minimal medium at $37^{\circ} \mathrm{C}$ until an $\mathrm{OD}_{600}$ of 0.4 was reached, whereupon supplementary amino acids were added at the following concentrations: L-lysine, L-phenylalanine and L-threonine at $100 \mathrm{mg} \mathrm{l}^{-1}$, L-isoleucine, L-leucine and L-valine at $50 \mathrm{mg} \mathrm{l}^{-1}$ and L-selenomethinone at $60 \mathrm{mg} \mathrm{l}^{-1}$. Cultivation was continued for $1 \mathrm{~h}$ at $37^{\circ} \mathrm{C}$ and the temperature was then decreased to $22^{\circ} \mathrm{C}$. After $30 \mathrm{~min}$ of equilibration time, protein production was induced by the addition of $1 \mathrm{~m} M$ IPTG and expression was allowed to proceed overnight. SeMet-substituted Psy-Lig was purified as described for the native protein and the extent of selenium incorporation was determined by electrospray ionization mass spectrometry of the labelled and native proteins. Enzymatic activity of the SeMet-substituted preparation was verified using the real-time assay described below.

\subsection{Crystallization and structure determination}

2.2.1. Crystallization and data collection. The SeMet incorporation was estimated to be $95 \%$ by mass spectrometry and the substituted enzyme was active in nick-sealing, with similar rates to those of the native protein (data not shown). wavelength MAD data set to $2.9 \AA$ resolution. This was followed by phase extension and phase modification in SHELXE (Sheldrick, 2010) using the high-resolution SeMet data to $1.65 \AA$ resolution, which allowed $A R P / w A R P$ (Langer et al., 2008) to build a partial model of 490 residues. Subsequent rounds of manual model building in WinCoot (Emsley \& Cowtan, 2004) and refinement in PHENIX (Afonine et al., 2012) gave the final model, which was deposited in the Protein Data Bank as entry 4d05 (Table 1). Psy-Lig crystallized in space group $C 2$ with two monomers in the asymmetric unit (Fig. 1a).

\subsection{Enzyme assays}

2.3.1. DNA substrates. To study the DNA ligase activity of Psy-Lig, two different assays were used: a TBE-urea gel-based endpoint assay to investigate activity on DNA substrates with single, double, gapped or mismatched nicks and a timeresolved assay using a molecular beacon (MB) to measure the rate of single nick sealing (Tang et al., 2003). To allow a good comparison between the two methods, the same nucleotide (nt) sequence was used as a basis for all oligonucleotide substrates in both assays (Table 2). In the case of the endpoint TBE-urea gel assay the $5^{\prime}$ end of the nicked strand was 
Table 2

Sequences of the oligonucleotides used to make ds-DNA substrates.

'Strand' refers to the moiety that the strand contributes to the nick or to its position in the complement. (P) indicates 5' phosphorylation; other modifications are as described in the text.

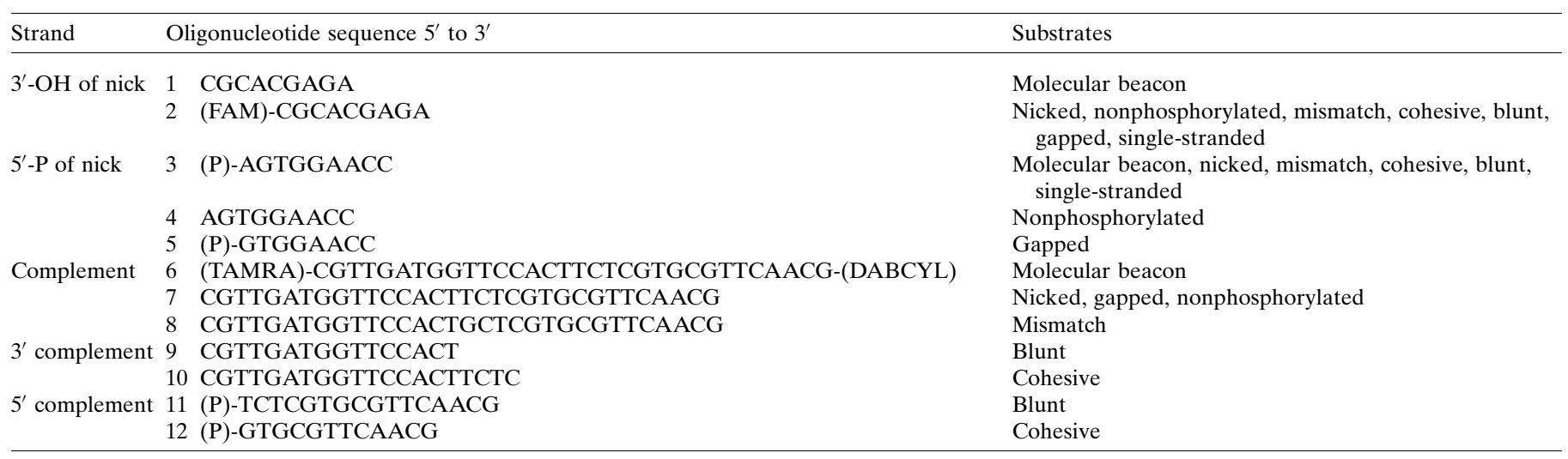

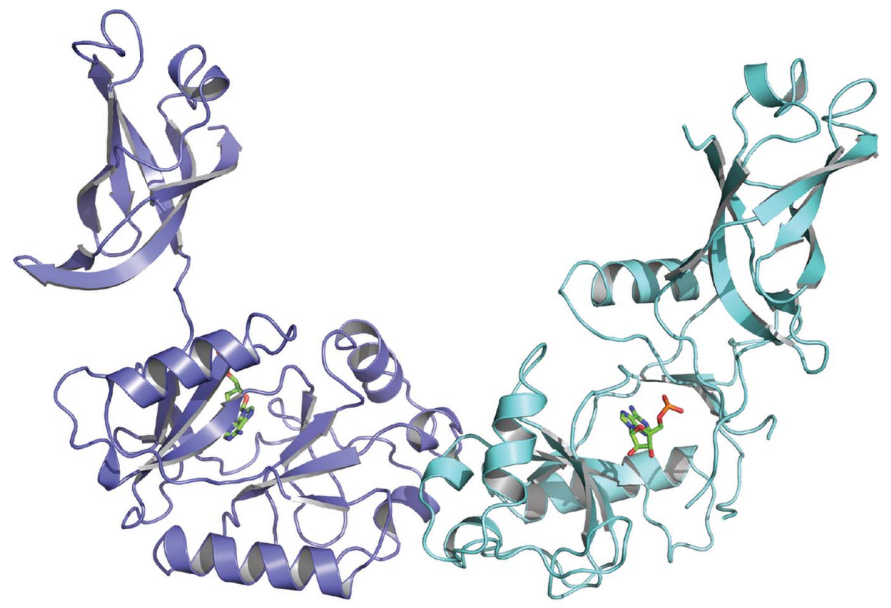

(a)

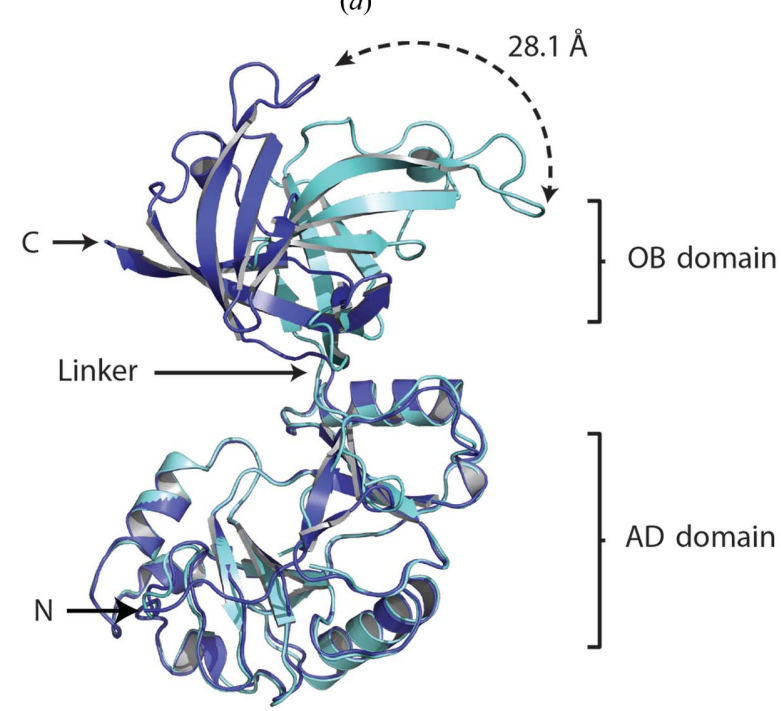

(b)

Figure 1

Overall fold of Psy-Lig chain $A$ (purple) and chain $B$ (blue). The covalently bound AMP is shown in green. (a) Chains in the asymmetric unit. (b) Superposition of chains by alignment of their AD domains. The dashed arrow indicates the distance between the $\mathrm{C}^{\alpha}$ atom of Gly191 of each monomer.
Table 3

Oligonucleotide components annealed to make different ds-DNA substrates as described in the text.

The numbers correspond to those in Table 2.

\begin{tabular}{llll}
\hline Substrate & $3^{\prime}$-OH of nick & $5^{\prime}$-P of nick & Complement \\
\hline Molecular beacon & 1 & 3 & 6 \\
Nicked & 2 & 3 & 7 \\
Mismatch & 2 & 3 & 8 \\
Cohesive & 2 & 3 & $10+12$ \\
Blunt & 2 & 3 & $9+11$ \\
Gapped & 2 & 5 & 7 \\
Nonphosphorylated & 2 & 4 & 7 \\
Single-stranded & 2 & 3 & - \\
\hline
\end{tabular}

labelled with 5-carboxyfluorescein (FAM), while in the realtime MB assay the fluorescent reporter moiety tetramethylrhodamine (TAMRA) was carried on the complementary strand and was quenched by the adjacent 4-(4'-dimethylaminophenylazo)benzoic acid (DABCYL) molecule, which was held in close proximity in the nicked state as described by Tang et al. (2003). HPLC-purified oligomers (Sigma) were used without any further purification. The ratio of oligonucleotides used to form the DNA duplex was 4:3 complement to nick strands (Table 3). In all cases 'substrate concentration' refers to the concentration of labelled nick strands in the reaction.

2.3.2. Gel-based assays. Gel-based endpoint assays were carried out as described previously (Magnet \& Blanchard, 2004; Cheng \& Shuman, 1997) with the modification that the $5^{\prime}$-fluorophore FAM was substituted for the $5^{\prime}-{ }^{32} \mathrm{P}$ label (Wang et al., 2013). Reaction volumes were $10 \mu \mathrm{l}$, unless otherwise specified, and consisted of $2.0 \mathrm{n} M$ enzyme, $80 \mathrm{n} M$ substrate, $0.1 \mathrm{~m} M$ ATP, $10 \mathrm{~m} M \mathrm{MgCl}_{2}, 1 \mathrm{~m} M$ DTT, $100 \mathrm{~m} M \mathrm{NaCl}$ and $50 \mathrm{~m} M$ Tris-HCl pH 8.0. Enzymatic activity was detected by conversion of the FAM-labelled 9 nt substrate oligonucleotide into an $18 \mathrm{nt}$ product after sealing of the nick in the doublestranded substrate. The bands were resolved by denaturing electrophoresis on a $20 \%$ acrylamide $/ 7 M$ urea/ $1 \times$ Trisborate-EDTA (TBE) gel, detected by fluorescence on a 
Table 4

Alignment of Psy-Lig with other ADLs of known structure.

Sequence homology is based on the full-length amino-acid sequences of ChlV-Lig and T7-Lig and the ligase domain of Mtu-Lig (residues 453-759). The Psy-Lig signal peptide was omitted from the primary sequence alignment. Structure-based alignments of the AD and OB domains were performed. Length is the number of matched amino acids in the alignment based on three-dimensional superposition. Root-mean-square deviation (r.m.s.d.) is calculated between $\mathrm{C}^{\alpha}$ atoms matched in the three-dimensional alignment. Aligned secondary-structural elements (SSEs) are the number of homologous SSEs in Psy-Lig identified in each target. The $Z$-score is the significance of the alignment based on Gaussian statistics.

\begin{tabular}{|c|c|c|c|c|c|c|c|c|c|}
\hline & \multirow[b]{2}{*}{$\begin{array}{l}\text { Sequence homology } \\
\text { (E-value) }\end{array}$} & \multicolumn{4}{|c|}{ AD domain } & \multicolumn{4}{|c|}{ OB domain } \\
\hline & & Length & $\begin{array}{l}\text { R.m.s.d. } \\
(\AA)\end{array}$ & $\begin{array}{l}\text { Aligned } \\
\text { SSEs }\end{array}$ & $Z$-score & Length & $\begin{array}{l}\text { R.m.s.d. } \\
\text { (A) }\end{array}$ & $\begin{array}{l}\text { Aligned } \\
\text { SSEs }\end{array}$ & $Z$-score \\
\hline MTu-Lig & 0.26 & 151 & 2.26 & 9 & 7.8 & 68 & 1.86 & 5 & 5.1 \\
\hline T7-Lig & $2.0 \times 10^{-4}$ & 157 & 1.91 & 10 & 8.5 & 72 & 1.72 & 5 & 6.7 \\
\hline
\end{tabular}

Pharos FX Plus imager (Bio-Rad) and quantified by band intensity using the ImageJ software (Schneider et al., 2012). The extent of ligation activity was taken as the ratio between the upper $18 \mathrm{nt}$ product band and the lower $9 \mathrm{nt}$ substrate band and was expressed as a percentage. Enzyme activity with the different DNA complexes was tested at $15^{\circ} \mathrm{C}$ for either $5 \mathrm{~min}$ (nicked, cohesive and mismatch substrates), $30 \mathrm{~min}$ (gapped substrate) or over a $25 \mathrm{~h}$ time course (blunt, nonphosphorylated and single-stranded substrates) using the enzyme concentrations specified in the figure captions. The optimal $\mathrm{NaCl}$ concentration for activity was tested at $30^{\circ} \mathrm{C}$ for $5 \mathrm{~min}$.

2.3.3. Molecular beacon assay. A time-resolved molecular beacon (MB) assay was carried out as previously described (Tang et al., 2003). Unless otherwise stated, the reaction conditions were $2.0 \mathrm{n} M$ Psy-Lig, $300 \mathrm{n} M$ substrate, $0.1 \mathrm{~m} M$ ATP, $10 \mathrm{~m} M \mathrm{MgCl}_{2}, 1 \mathrm{~m} M$ DTT, $100 \mathrm{~m} M \mathrm{NaCl}, 50 \mathrm{~m} M$ Tris pH 8.0. Reactions were carried out in a 96-well plate (Corning, black flat-bottom low protein-binding surface) in a volume of $100 \mu$ l. Fluorescence was measured using a Spectromax M2 ${ }^{\mathrm{e}}$ (Molecular Devices) with an excitation wavelength of $521 \mathrm{~nm}$ and an emission wavelength of $578 \mathrm{~nm}$. The assay setup was allowed to equilibrate at $30^{\circ} \mathrm{C}$ for at least $30 \mathrm{~min}$ before initiation by the addition of enzyme. Reactions were mixed for $5 \mathrm{~s}$ subsequent to enzyme addition and the fluorescence emission was recorded every $5 \mathrm{~s}$ for $30 \mathrm{~min}$. The kinetics of nick sealing by Psy-Lig were investigated by varying the concentration of either ds-DNA or ATP while the other substrate was kept constant and in excess. Steady-state kinetics were measured for concentrations of the MB between 11.25 and $300 \mathrm{n} M$ in the presence of $0.1 \mathrm{~m} M$ ATP and $1.0 \mathrm{n} M$ enzyme; however, for the reasons described in $\S 3$ only the concentration range between 11.25 and $225 \mathrm{n} M$ was used for the calculation of $K_{\mathrm{m}}$ and $k_{\text {cat }}$. ATP kinetics were measured at ATP concentrations between 0 and $50 \mu M$ with $300 \mathrm{n} M \mathrm{MB}$ substrate and $2.0 \mathrm{n} M$ Psy-lig. To quantify the fluorescence change resulting from nick sealing, calibration curves were constructed by serial dilution of the singly nicked MB substrate and the fully ligated substrate where the two short oligomers were replaced with an $18 \mathrm{nt}$ strand as described in Tang et al., 2003). The conversion value used in calculations was the difference between these as the nicked substrate had significant background fluorescence. Kinetic rates were calculated from the initial slope of the progress curves and were fitted to the Michaelis-Menten equation using the kinetics module of SigmaPlot.

\section{Results}

\subsection{Crystal structure of Psy-Lig}

3.1.1. Overall structure. Each Psy-Lig monomer has a large (172-residue) N-terminal AD domain comprising two fourstranded $\beta$-sheets surrounded by five $\alpha$-helices and a smaller (77-residue) OB domain comprising a five-stranded $\beta$-barrel and a single $\alpha$-helix. All backbone and side chains are resolved for chain $A$ (Psy-Lig- $A$ ), but in chain $B$ (Psy-Lig- $B$ ) eight residues had no electron density and were left out of the model: four in the $\mathrm{N}$-terminus, two in the $\mathrm{C}$-terminus and two in the loop between strands $\beta 7$ and $\beta 8$. The two domains are connected by an eight-residue linker, and in both Psy-Lig chains these adopted the open conformation typical of the enzyme-adenylate intermediate, in which the DNA-binding surfaces of the two domains face away from each other (Nair et al., 2007; Tomkinson et al., 2006; Shuman, 2009). The two chains in Psy-Lig have a $C^{\alpha}$ r.m.s.d. difference of $3.45 \AA$; however, when they are structurally aligned based only on the $\mathrm{AD}$ domains it is clear that this arises primarily from a different orientation of their $\mathrm{OB}$ domains about the linker (Fig. 1b). When the AD domains are aligned, the measured distance of the $\mathrm{C}^{\alpha}$ atom of Gly191 in the OB domain of each chain is $28.1 \AA$. If the $\mathrm{AD}$ and $\mathrm{OB}$ domains are aligned separately, the r.m.s.d. values are only 0.63 and $0.72 \AA$, respectively. The more complete electron density of Psy-Lig- $A$ is reflected by its lower $B$ factor $\left(11.6 \AA^{2}\right)$ compared with chain $B\left(32.8 \AA^{2}\right)$. For this reason, it is chain $A$ which is referred to in the subsequent sections of the discussion unless otherwise specified.

A structure-based homology search using the PDBeFold server found the closest matches to the overall Psy-Lig structure were the adenylated and DNA-bound structures of the Chlorella virus ATP-dependent DNA ligase (abbreviated ChlV-Lig-AMP and ChlV-Lig-DNA, respectively; PDB entries 1fvi and 2q2t; Nair et al., 2007; Odell et al., 2000). Less 
significant matches were also found to ATP-dependent DNA ligases from the T7 phage (T7-Lig; PDB entry 1a0i; Subra-

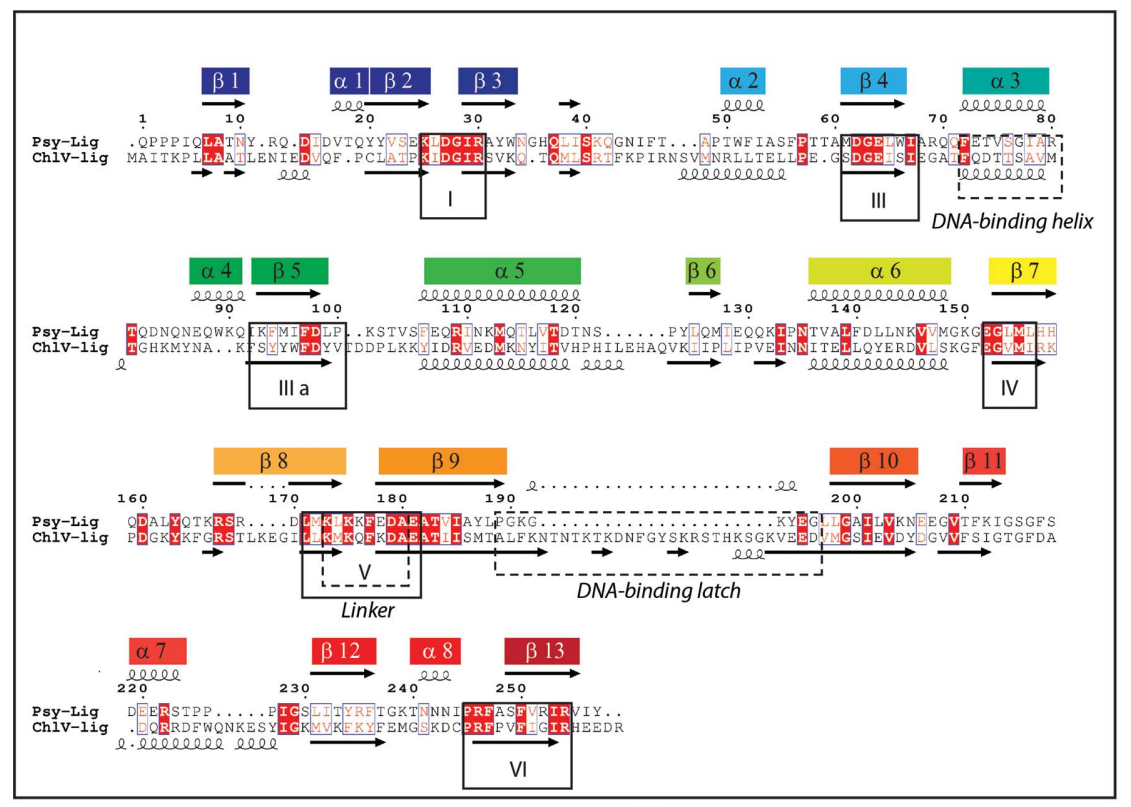

(a)

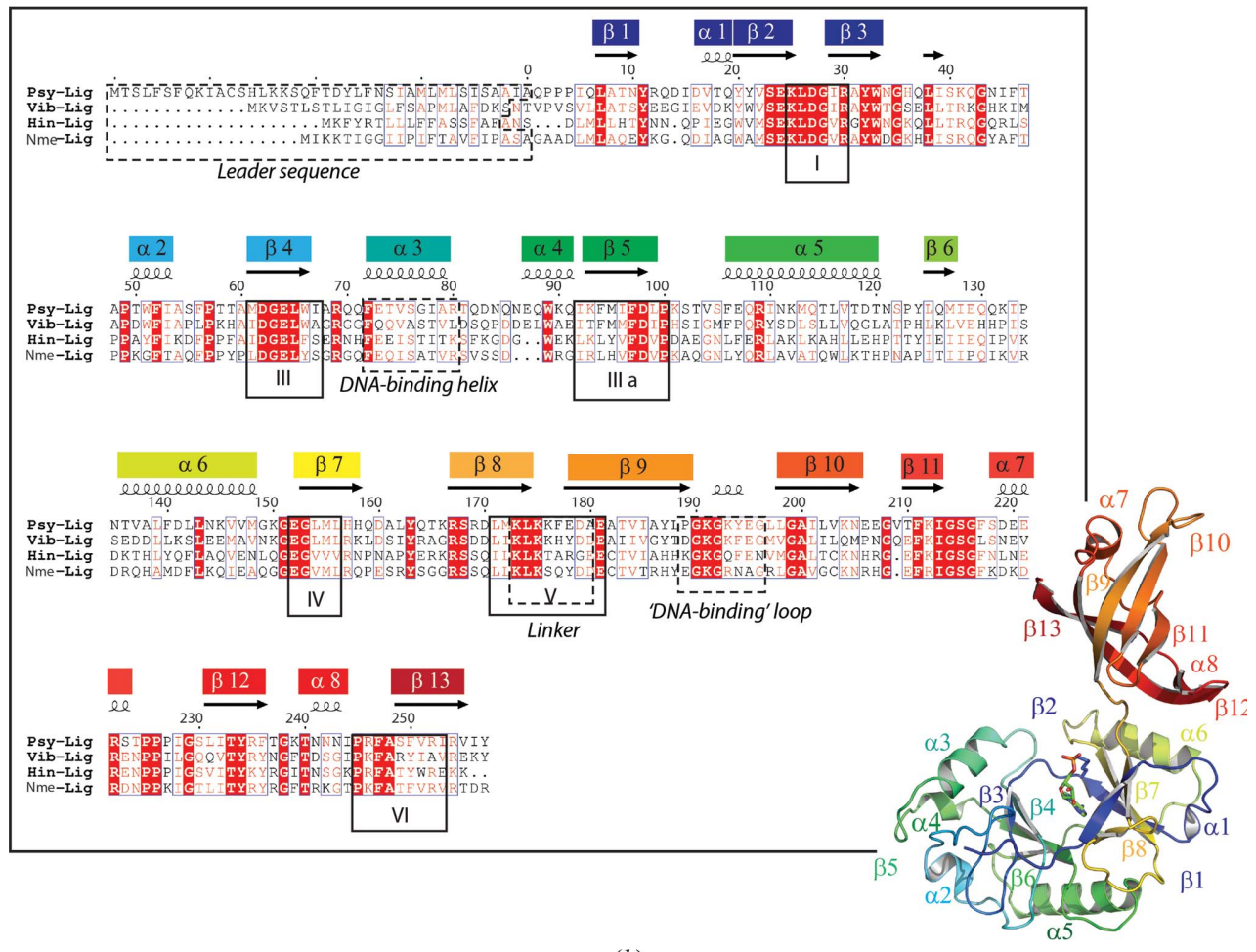

(b)

\section{Figure 2}

Sequence alignments of Psy-Lig with other ATP-dependent DNA ligases. Fully conserved residues are shaded red; partially or homologously conserved residues are shown in red text. Structural features discussed in the text and the conserved motifs of the nucleotidyltransferase enzymes are indicated in boxes, with numbering corresponding to the conventions given in Shuman \& Lima (2004). $\alpha$-Helices are indicated by curl symbols and $\beta$-strands by arrows. Filled boxes above the sequences give the numbering of the secondary-structural elements of Psy-Lig as referred to in the text, and correspond to the colours and numbering used in the ribbon diagram (inset). (a) Structure-based alignment between Psy-Lig and ChlV-Lig constructed using PDBeFold. (b) Sequence-based alignment of Psy-Lig with biochemically characterized ligases from $H$. influenzae (Hin-Lig), N. meningitidis (Nme-Lig) and A. salmonicida (Vib-Lig). manya et al., 1996) and the ligase domain of M. tuberculosis LigD (Mtu-Lig; PDB entry 1vs0; Akey et al., 2006) (Table 4). Separate searches for Psy-Lig using the only the AD (residues 1-176) or OB domains (residues 177-257) revealed a significant difference in structure between the OB domains from Psy-Lig and Mtu-Lig. While the AD domain is very similar in all five structures, the OB domain of Psy-Lig more closely resembles those of the two viral proteins rather than the other bacterial homologue. These structural differences are reflected by the extremely divergent primary sequences between the two bacterial proteins, which have almost no significant similarity at the amino-acid level (Table 4). A structure-based sequence alignment between PsyLig and ChlV-Lig found 27\% identity (56 residues) and 30\% similarity (62 residues; Fig. 2a). All of the conserved motifs of the nucleotidyltransferase family are present in Psy-Lig, as is the $\alpha 3$ helix which was shown to interact with the minor groove of the $3^{\prime}$ side of the nicked strand of the DNA in the ChlV-Lig-DNA structure (Nair et al., 2007). The most significant differences are the truncation of the OB-domain $\beta 9-\beta 10$ loop and a shorter $\alpha 7$ helix in Psy-Lig relative to ChlVLig, which are discussed in more detail below.

3.1.2. Enzyme adenylate and active site. AMP bound in the active site was clear in the observed electron density, covalently linked to Lys25 via a phosphoamide bond to the side-chain $\mathrm{N}^{\zeta}$ atom, which is consistent with exposure of the protein to high levels of ATP during purification (Fig. 3). Nine sulfate molecules were also resolved in the electron density, one of which is located in the active site of chain $A$. A sulfate ion at the equivalent position in ChlV-Lig-AMP occupies the binding site of the nicked $5^{\prime}$ DNA in ChlV-Lig-DNA, a structure which is also likely to be 
the case here. As in other ligase-adenylate structures, the AMP is in the anti conformation, with the adenine nucleotide

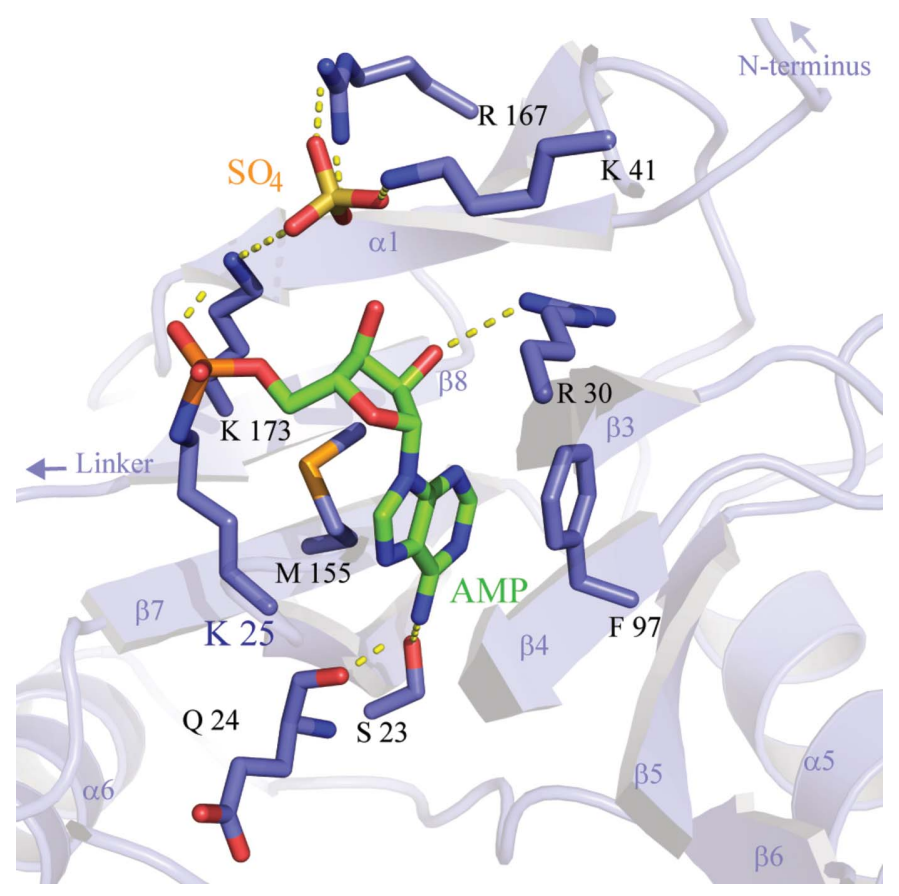

Figure 3

Active-site structure of Psy-Lig- $A$. The nucleotide cofactor is depicted and labelled in green and the sulfate ion is in yellow. Lys 25 which is covalently attached to the AMP is labelled in bold; all residues making contacts with the cofactor and ion are shown as purple sticks. Secondarystructural elements of the AD domain are labelled in light purple and correspond to the notation used in Fig. 2.

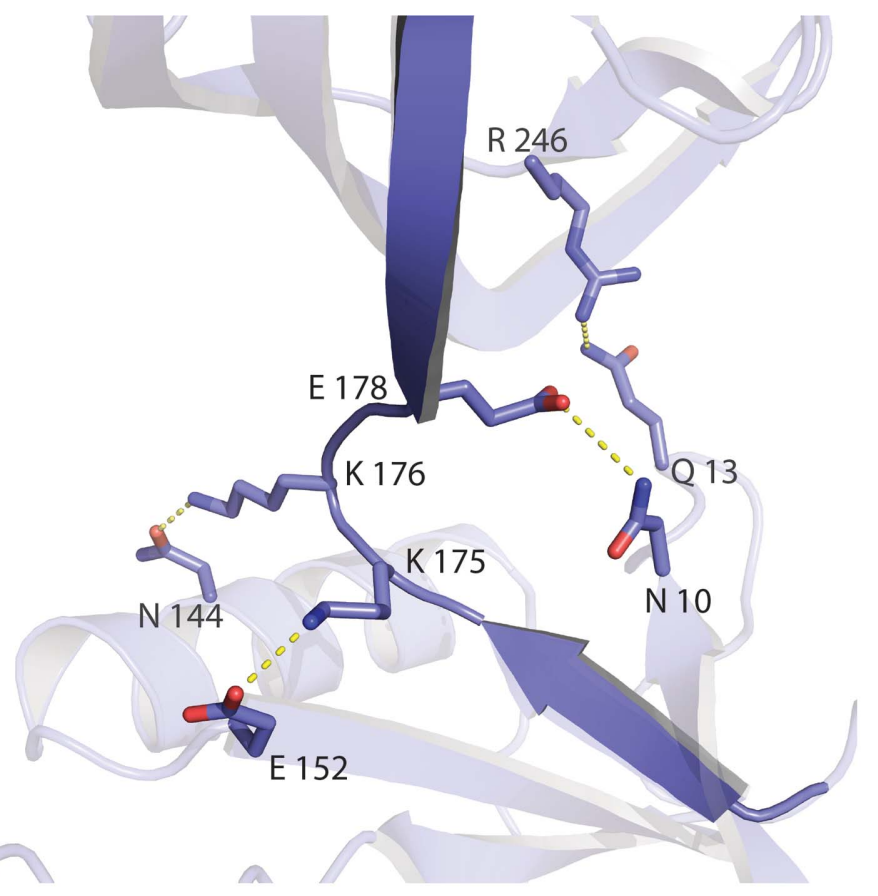

Figure 4

(a) base stacked between the hydrophobic side chains of Phe97 in motif IIIa and Met155 in motif IV. The side chains of Ser32 and Glu24 provide hydrogen bonds to the exocyclic N6 of the base, while the side chain of Arg30 in motif I is positioned to hydrogen bond to the ribose $\mathrm{O} 2$. Contacts to the sulfate are made by Lys41 in the $\beta 3-\alpha 2$ loop and Arg167 in $\beta 8$. Lys173 of motif $\mathrm{V}$ also makes a bifurcated bond to the sulfate and the nonbridging phosphate $\mathrm{O}$ atom of the adenylate (Fig. 3).

3.1.3. Domain dynamics and modelling of DNA interaction. Interactions between the $\mathrm{AD}$ and $\mathrm{OB}$ domains of PsyLig- $A$ include hydrogen bonds between Arg246 (loop $\alpha 8-\beta 13$ ) and Gln13 (loop $\beta 1-\alpha 1$ ), and between Gly238 (loop $\beta 12-\alpha 8$ ) and Asn10 ( $\beta 1)$ via hydrogen bonding to the side chain of the linker residue Glu178. The AD domain also forms a salt bridge to the linker from Glu152 of $\beta 7$ to Lys175 and a hydrogen bond from Asn144 of $\alpha 6$ to Lys176 (Fig. 4a). In PsyLig- $B$ the $\mathrm{OB}$ domain is tilted further away from the $\mathrm{AD}$ domain, which equates to a one-residue turn in the linker-AD hydrogen-bonding pattern. Instead, Glu152 forms an ion pair with Lys176 rather than Lys175, which has no intramolecular hydrogen bonds (Fig. 4b). Interactions between Glu178 and Asn10 and between Arg246 and Gln13 are not present in PsyLig- $B$. Superposition of the structures of Psy-Lig- $A$, ChlVLig-AMP and ChlV-Lig-DNA using only their AD domains for alignment shows that the OB domain of Psy-Lig- $A$ occupies an intermediate position between those of the DNAbound (open) and DNA-free (closed) forms of ChlV-Lig (Fig. 5a). The top of $\alpha 7$ is tilted around $25 \AA$ more towards the DNA-bound position than ChlV-Lig-AMP, but the OB domain would still need to swivel about the linker to be oriented the same as in ChlV-Lig-DNA. The position of the OB domain of Psy-Lig- $B$ is closer to that of ChlV-Lig-AMP.

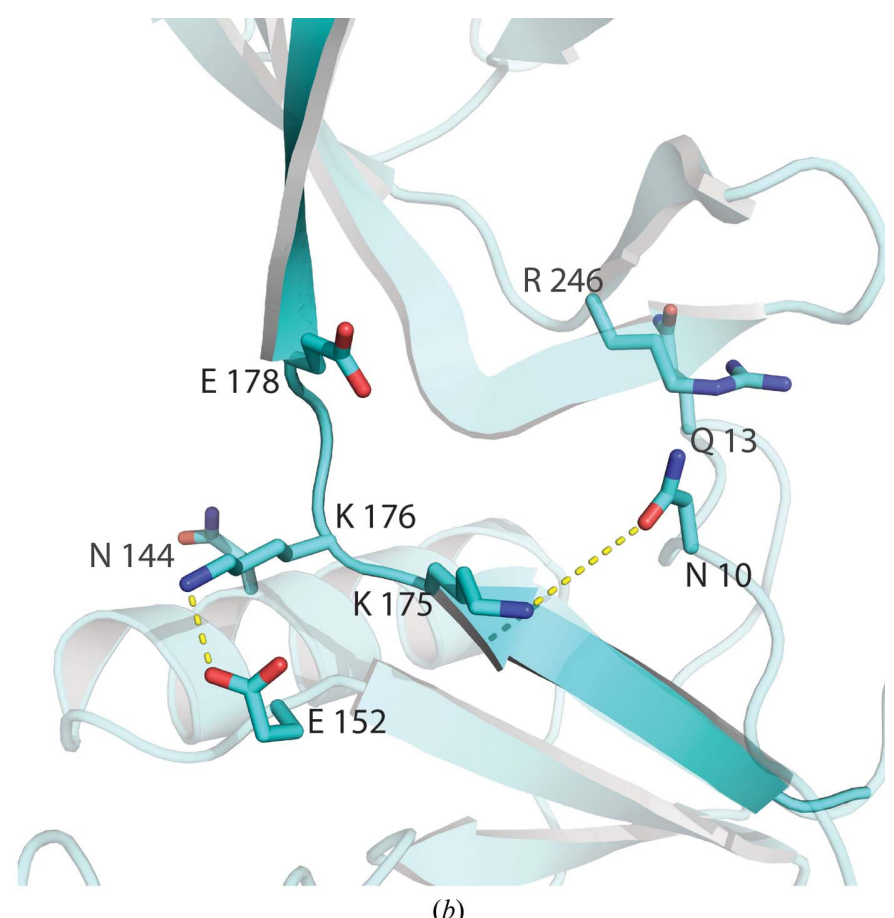

(b)

Conformation of the linker between the $\mathrm{AD}$ and $\mathrm{OB}$ domains. (a) Chain $A,(b)$ chain $B$. 
To gain insight into its possible DNA-binding interactions, the DNA-bound orientation of Psy-Lig was modelled by superimposing the $\mathrm{OB}$ domain onto the $\mathrm{OB}$ domain of the ChlVLig-DNA structure (PDB entry 2q2t; Fig. 5b). This involved a swivel of $180^{\circ}$ about the linker but did not require a translation relative to the $\mathrm{AD}$ domain. The DNA from the ChlV-LigDNA structure fits well into the concave surface of the Psy-Lig OB domain, with the complementary strand running $3^{\prime}$ to $5^{\prime}$ from the linker to the loop end, while the nicked strand runs $3^{\prime}$ to $5^{\prime \prime}$ across the flatter $\mathrm{AD}$ domain surface. Together, the two Psy-Lig domains encircle just over $180^{\circ}$ of the circumference of the DNA duplex, in contrast to the complete encirclement by ChlV-Lig (Fig. $5 c$ ).

3.1.4. Surface topology and electrostatics. Analysis of the surface topology and electrostatics of Psy-Lig indicate DNAinteracting residues on both binding faces of the $\mathrm{OB}$ and $\mathrm{AD}$ domains as well as positive surface potentials that would contribute to DNA binding (Fig. 6a). The OB domain has a positively charged groove running down its concave surface which could accommodate the unbroken complementary strand of the DNA duplex (Figs. $6 c$ and $6 d$ ). Partial positive charges in the depth of the groove are provided by the amide $\mathrm{N}$ atoms of residues Ile213, Gly214, Ser215 and Gly216 in the loop between $\beta 11$ and $\alpha 7$, Gly199 and Ala200 in the loop between $\beta 9$ and the beginning of strand $\beta 10$, and Ser249, Ala248, Phe247 and Pro245 in the loop between $\beta 12$ and $\alpha 8$ (the VI motif of nucleotidyltransferases). The sides of the groove are formed by the bulky side chains of residues Lys212, Ser215, Arg222, Asn241, Thr240 and Phe247. The OB-domain loop between $\beta 9$ and $\beta 10$ follows the curve of the DNA backbone (Fig. $5 b$ ) and occupies a homologous position to the latch region of ChlV-Lig-DNA. At the tip of the OB-domain loop, a small $3_{10^{-}}$-helix contains two lysine residues, Lys191 and Lys193, which form a rigid fork with their side chains pointing to either side of the groove (Figs. $6 c$ and $6 d$ ). When the OB domain is oriented in the DNA-binding position, this fork is positioned to straddle the DNA backbone and interact with both the major and minor grooves of the duplex (Fig. $5 b$ ). In Psy-Lig- $A$ the side chain of Arg222 ( $\alpha 7)$ stacks against the side chain of Tyr194, which in turn lies flat against Lys193, forming a continuous structure along one edge of the groove (Figs. $6 c$ and $6 d$ ). Arg222 also makes two hydrogen bonds (via its $\mathrm{N} 1$ and $\mathrm{O}$ atoms) to the main-chain atoms of Leu198 (at the beginning of $\beta 10$ ), one hydrogen bond from N2 to Gly214 (in the $\beta 11-\alpha 7$ loop) and a bifurcated bond from its main-chain $\mathrm{N}$ atom to Ser218 and Asp219 (at the N-terminal end of $\alpha 7$ ). A main-chain interaction between Leu197 and Gly190 pinches across the base of the loop. A second groove on the DNAinteracting face of the $\mathrm{AD}$ domain is formed by $\alpha 3$ and residues Lys41, Gln42 and Asn 44 of the $\beta 3-\alpha 2$ loop (Fig. $6 b$ ). This would be positioned to fit the $3^{\prime}$ strand of the nicked DNA, and runs across the pocket in whcih the AMP is covalently bound to Lys 25 . The $\beta 3-\alpha 2$ loop is stabilized by numerous interactions, including main chain to main chain interactions between Ser40 and Gly43, between Ser40 and Asn44 and between Leu38 and Phe46, main chain to side chain interactions between His36 and Asn34, between Asn37 and Asn34 and between Asn 44 and Ser40, and side chain to side chain interactions between Asn34 and Asn37 and between Ser40 and Asn44. A hydrogen bond between the main chain of Asp83 and the side chain of Thr47 links the two lips of the groove furthest from the AMP site, and an interaction between the side chains of Asp62 and Tyr163 tethers the $\beta 3$ $\alpha 2$ loop to one of the two $\beta$-sheets that form the core of the $\mathrm{AD}$ domain. The groove continues to the other side of the active site, where a cluster of positive charges provided by Lys173 and Lys 175 of the linker and Asn 10 from $\beta 1$ could provide contacts to the $5^{\prime}$-end of the nicked strand, while

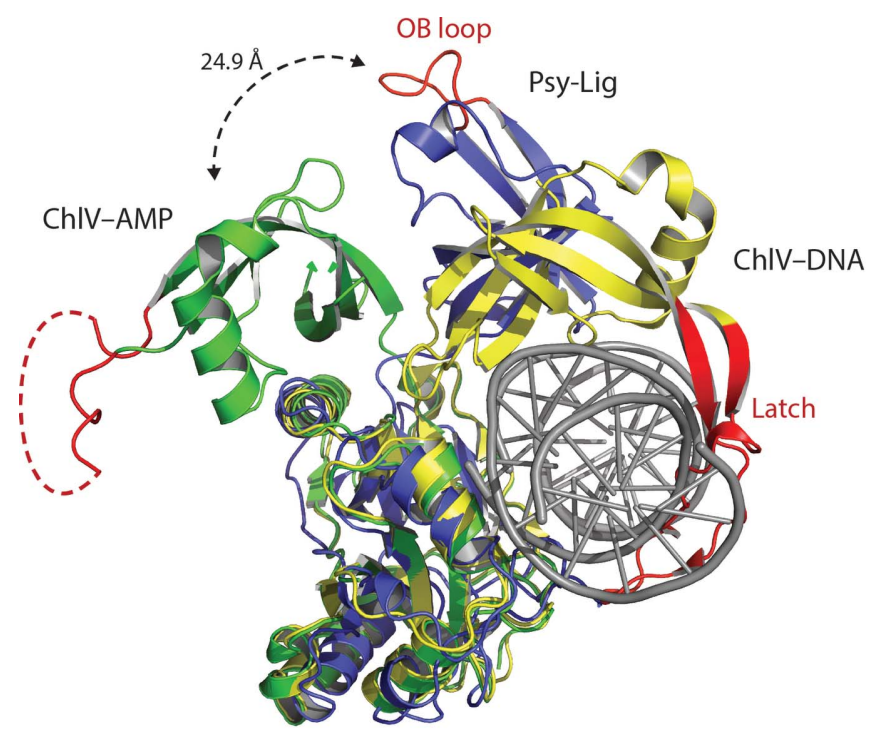

(a)

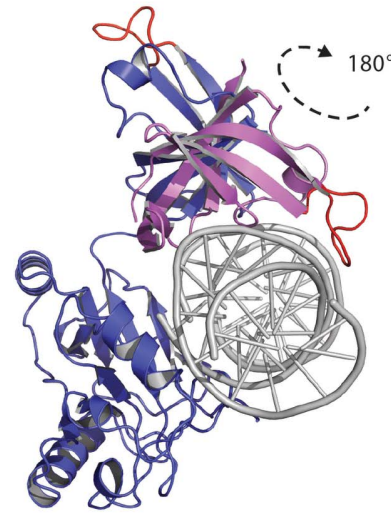

(b)

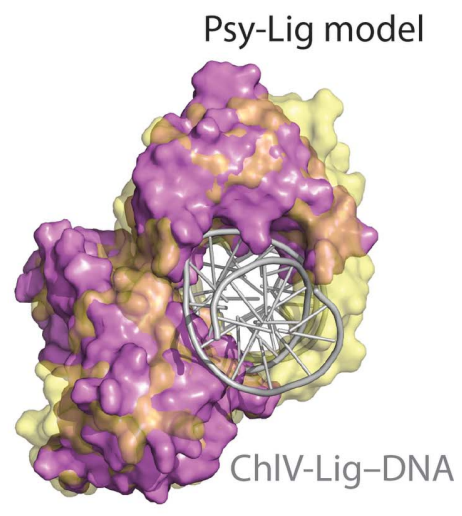

(c)
Figure 5

Comparison of the tertiary structure of Psy-Lig with that of ChlV-Lig. (a) Superposition of Psy-Lig chain $A$ (purple) with ChlV-Lig-AMP (green, PDB entry 1fvi) and ChlV-Lig-DNA (yellow, PDB entry 2q2t). The DNA-binding latch of ChlV-Lig and the homologous loop of Psy-Lig are coloured red. The unstructured residues of ChlV-Lig-AMP are indicated as a dashed line. DNA is shown in grey. (b) Psy-Lig modelled in the DNAbound conformation by superposition of the Psy-Lig OB domain with the ChlV-Lig-DNA OB domain-DNA complex. The original adenylated PsyLig structure (purple) and the re-oriented position (pink) are shown as ribbons. The DNA from the ChlV-Lig-DNA structure is shown in grey. (c) Surface of the Psy-Lig DNA-bound model (pink) superposed with the ChlV-Lig-DNA structure (yellow, transparent), showing incomplete encirclement of the DNA by Psy-Lig. 
Arg169, Arg167 and Lys166 from the $\beta 7-\beta 8$ loop form a positively charged surface for interaction with the backbone of the complementary strand. Hydrogen bonds between Gln6 and Gln164 and between Ala8 and Arg167 link the N-terminal $\beta 1$ strand to the $\beta 7-\beta 8$ loop and position the $\mathrm{N}$-terminus to lie alongside the $\beta 3-\alpha 2$ loop.

\subsection{Enzyme activity of Psy-Lig}

3.2.1. Ligation of different DNA substrates. The ligase activity of Psy-Lig on 18 bp DNA duplexes containing centrally placed single-stranded or double-stranded breaks was investigated by a gel-based endpoint assay. Efficient sealing of a perfectly matched 5 -phosphorylated singly nicked substrate in the presence of ATP and $\mathrm{MgCl}_{2}$ proceeded within $5 \mathrm{~min}$ at $15^{\circ} \mathrm{C}$ as shown by the appearance of the $18 \mathrm{nt}$ product band on a denaturing TBE-urea gel at the expense of the $9 \mathrm{nt}$ substrate (Fig. 7a). The extent of nick ligation when quantified by integration of band intensity was dependent on the enzyme concentration, with a linear range between 0.2 and $4.0 \mathrm{n} M$ (Fig. $7 b$ ). In addition to sealing a singly nicked fully matched double-stranded DNA substrate, Psy-Lig was also able to ligate a cohesive-ended double-stranded break and a single nick with a $1 \mathrm{bp}$ mismatch at the $3^{\prime}-\mathrm{OH}$ position of the nick, albeit with reduced efficiency (Fig. $7 b$ ). Ligation of a bluntended double-stranded break (Fig. 7c) and a $1 \mathrm{nt}$ gapped substrate (Fig. 7b, inset) was also detected when high Psy-Lig concentrations and extended incubation times were used; however, no activity was seen with a nonphosphorylated 5 '-nicked strand or single-stranded DNA (data not shown).

3.2.2. Steady-state kinetics and salt optima. The enzyme kinetics of Psy-Lig were measured using the real-time MB assay. As expected, the rate of nick sealing increased with the concentration of the DNA substrate (Fig. 8a). This increase obeyed the Michaelis-Menten model up to a substrate concentration of $225 \mathrm{n} M$ and was used to calculate a $K_{\mathrm{m}}$ of 124 $\pm 37 \mathrm{n} M$ for nicked DNA and a $k_{\text {cat }}$ of $0.05 \mathrm{~s}^{-1}$. At concentrations of molecular beacon above $300 \mathrm{n} M$ the reaction velocity decreased with increasing substrate concentration, and examination of the MB progress curves revealed that this was owing to a delay in the onset of the fluorescence response. TBE-urea gel experiments with substrate concentrations between 25 and $1200 \mathrm{nM}\left(5 \mathrm{~min}\right.$ at $\left.30^{\circ} \mathrm{C}\right)$ showed no evidence of substrate inhibition (data not shown); thus, this behaviour
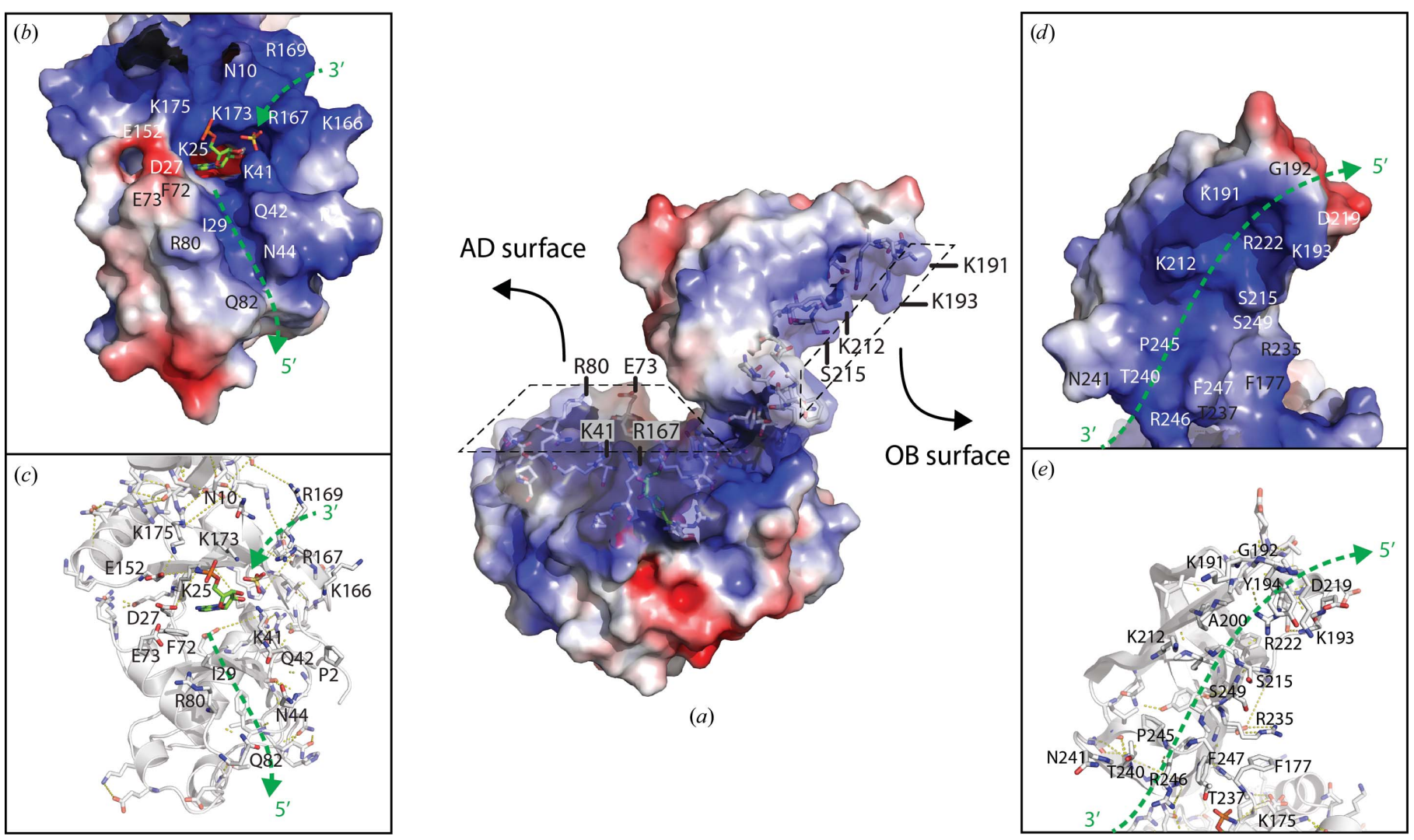

\section{Figure 6}

Psy-Lig- $A$ coloured by electrostatic surface potential. The surface potential was generated using APBS (Dolinsky et al., 2007), with positively charged areas shown in blue and negatively charged areas in red. (a) Overview of the Psy-Lig structure with residues predicted to be involved in DNA interactions shown as sticks. $(b)$ Surface and $(c)$ important residues of the AD domain looking at the active site. The AMP cofactor and sulfate ion are shown as sticks. Green arrows indicate the approximate positions of the nicked DNA strands based on the model shown in Fig. 5. (d) Surface residues and $(e)$ residues of the $\mathrm{OB}$ domain looking towards the DNA-binding site predicted by the model. The green arrow indicates the approximate position of the complementary DNA strand in the OB groove. 
can be attributed to a limitation of the assay, possibly because high concentrations of beacon lead to intermolecular quenching. Reaction rates measured with increasing concentrations of ATP $(0-50 \mu M)$ showed that ATP is an essential cofactor for DNA ligation, with a $K_{\mathrm{m}}$ of $3.8 \pm 0.7 \mu M$, and saturates at around $30 \mu M$ (Fig. $8 b$ ). No inhibition was seen with ATP concentrations up to $0.5 \mathrm{~m} M$ (data not shown). To investigate the effect of metal ions and ionic strength on nick-sealing activity, Psy-Lig was assayed at a range of $\mathrm{MgCl}_{2}$ and $\mathrm{NaCl}$ concentrations. $\mathrm{MgCl}_{2}$ was required for Psy-Lig activity, with an optimal concentration between 1 and $5 \mathrm{mM}$ (Fig. $8 c$ ). By contrast, $\mathrm{NaCl}$ was not necessary for activity, but concentrations above $100 \mathrm{~m} M$ had an inhibitory effect (Fig. $8 d$ ). To confirm that the decrease in activity was owing to the enzyme rather than the behaviour of the $\mathrm{MB}$ at high salt concentration, the $\mathrm{NaCl}$ assay was repeated using the gelbased endpoint assay, with the same result (Fig. $8 d$, dashed line).

\section{Discussion}

\subsection{Mechanistic implications of the Psy-Lig structure for DNA binding}

The intrinsic ability of Psy-Lig to efficiently seal breaks in DNA, coupled with the absence of obvious DNA-binding domains in the crystal structure, suggests that this enzyme must have a mechanism of engaging its DNA substrate which does not rely on the ordering of large flexible loop regions in the presence of DNA, but more likely takes place through interactions with shorter highly structured motifs and specific charged residues. The most salient difference between the ChlV-Lig and Psy-Lig structures is the absence of the 30-amino-acid lysine-rich DNA-binding latch region which is disordered in ChlV-Lig-AMP and structured in the DNAbound form (Nair et al., 2007; Odell et al., 2000). Point mutations in the ChlV-Lig latch diminished the nick-sealing activity, and replacement of the latch by a short linker reduced

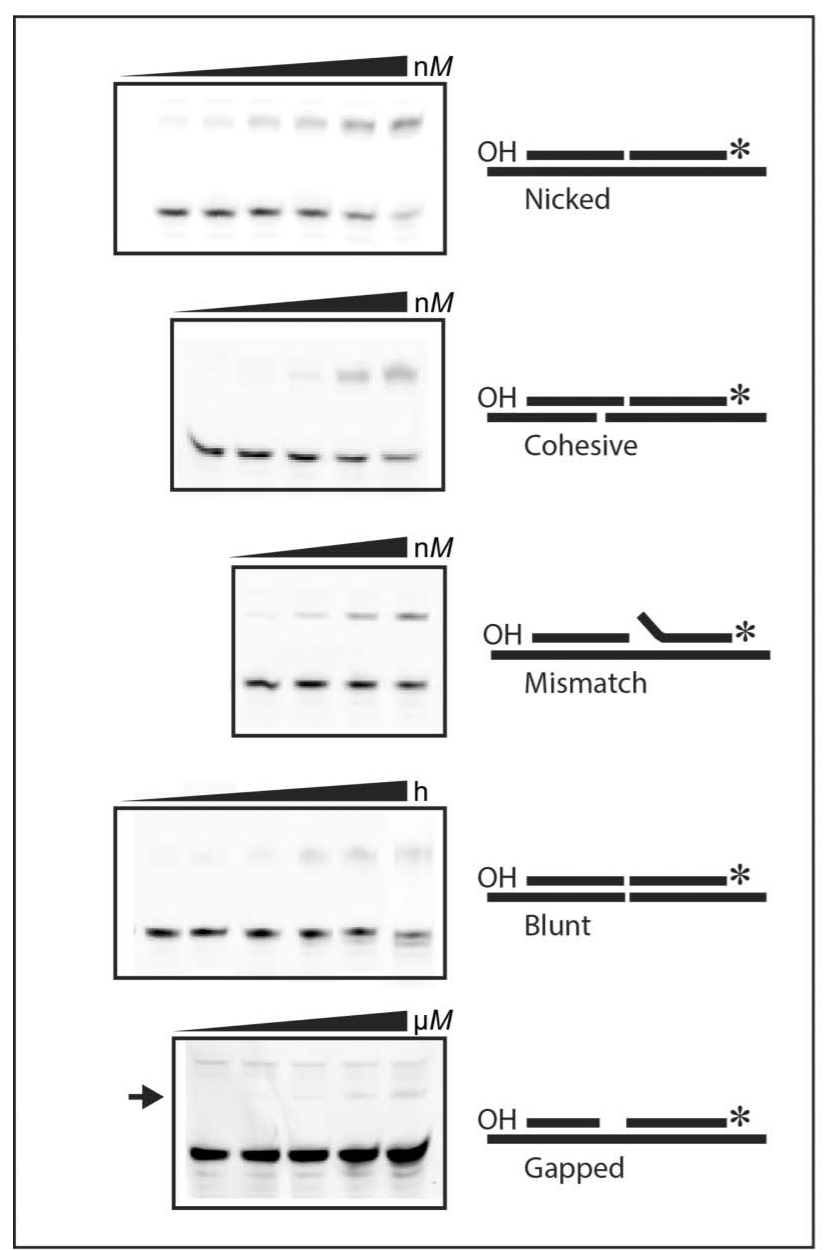

(a)

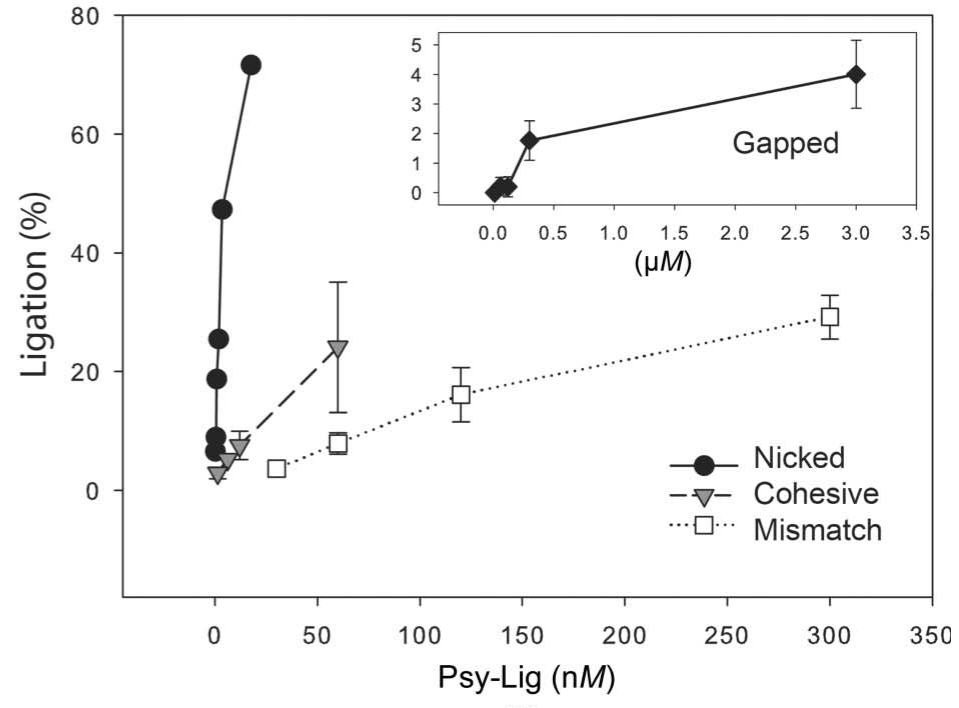

(b)

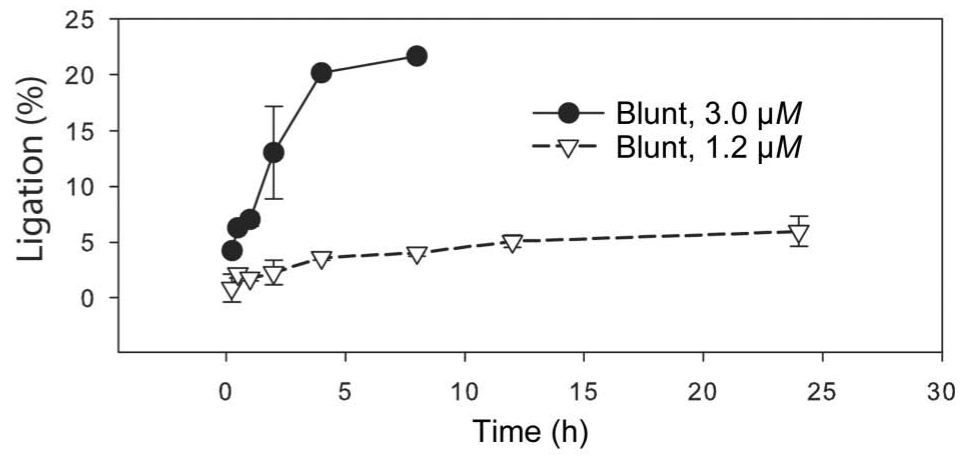

$(c)$

\section{Figure 7}

Ligation activity of Psy-Lig with different DNA substrates. (a) Schematic representation of DNA substrates and representative results of ligation on TBE-urea gels. The samples for the blunt substrate gel are for a $3.0 \mu M$ enzyme concentration over $8 \mathrm{~h}$. The image contrast for the gapped substrate gel has been adjusted to allow visualization of the faint bands from ligation. Integration of bands was carried out prior to this adjustment. (b) Percentage of substrate ligated in $5 \mathrm{~min}$ for nicked, cohesive and mismatch substrates (main figure) and gapped substrate after 30 min (inset) as a function of enzyme concentration. (c) Percentage of blunt substrate ligated over 8 or $24 \mathrm{~h}$ for two Psy-Lig dilutions. Ligation activity was quantified by integration of band intensity and is expressed as the percentage of upper (ligated) band relative to the sum of the two bands. Measurements are the mean of three replicate experiments; error bars represent the standard deviation from the mean. 
DNA binding by tenfold and increased the sensitivity to $\mathrm{NaCl}$ (Nair et al., 2007). The Psy-Lig OB domain has a shorter loop (eight amino acids) rather than the latch, and this is fully resolved in the electron density despite the absence of DNA (Fig. 5). The results of nick-sealing assays with Psy-Lig show that it is able to efficiently seal single-stranded breaks in DNA (Figs. 7 and 8) and was partially functional at $\mathrm{NaCl}$ concentrations of up to $400 \mathrm{~m} M$ (Fig. $8 d$ ). The loop contains a pair of lysine residues, which we postulate to be involved in DNA binding (Figs. $6 b$ and $6 c$ ). The whole loop is stabilized by hydrogen bonds in the 310 -helical element and between the base of the loop and the main OB domain via Arg222. In the ChlV-Lig-DNA structure, the latch encircles the DNA duplex to form hydrogen bonds to the AD domain. In Psy-Lig the equivalent position in the $\mathrm{AD}$ domain, a loop between $\beta 3$ and $\alpha 2$, is moved $2.9 \AA$ towards the $\mathrm{OB}$ domain relative to the position in ChlV-Lig, and this makes the groove in which the $3^{\prime}$-nicked strand would lie tighter (Figs. $6 d$ and $6 e$ ). The $\mathrm{N}$-terminus of the Psy-Lig protein points towards the DNAbinding face under the $\beta 3-\alpha 2$ loop, while in the ChlV-Lig structure it points away from the AD domain in both the DNA-bound and DNA-free structures. The other side of the groove is formed by the $\alpha 3$ DNA-binding helix, where Arg80 and Gln 82 at the end of the helix contribute positive and polar side chains to the groove and make it deeper relative to the ChlV-Lig protein, in which the equivalent positions are Met83 and Gly85. The OB domain of T7-Lig closely resembles that of Psy-Lig in that it also has a shorter (14-amino-acid) $\beta 9-\beta 10$ loop rather than the long latch of ChlV-Lig. Instead, T7-Lig has an additional 21-amino-acid loop, in which nine residues are unstructured, that extends between the equivalent positions of $\alpha 7$ and $\beta 12$. In Psy-Lig the $\alpha 7$ helix is much shorter

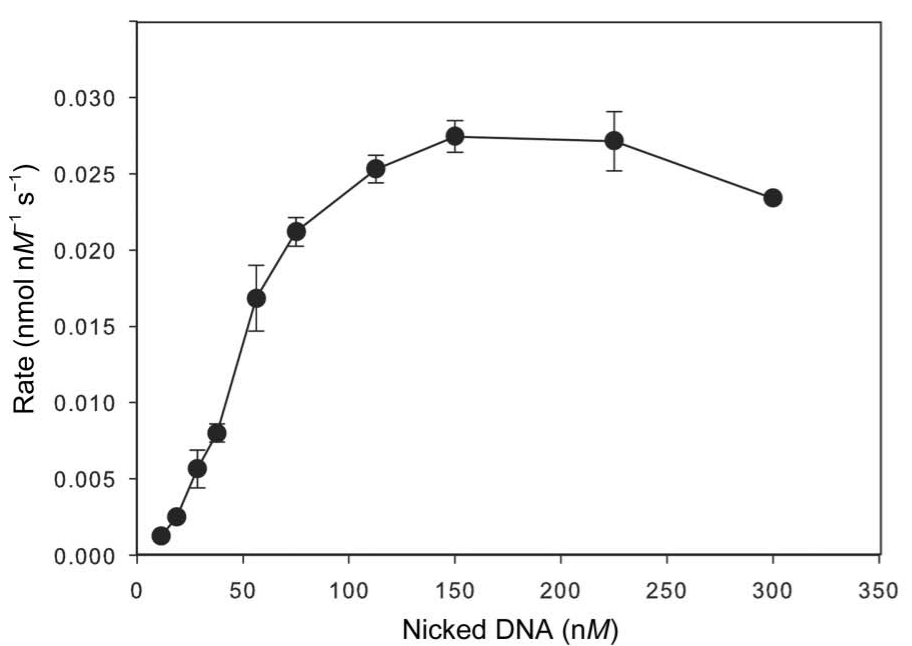

(a)

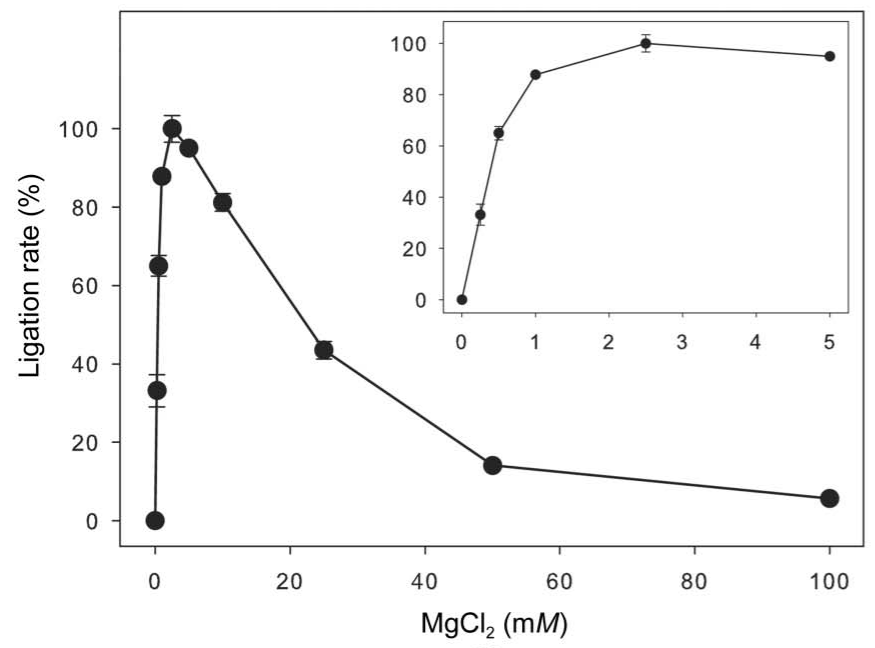

(c)

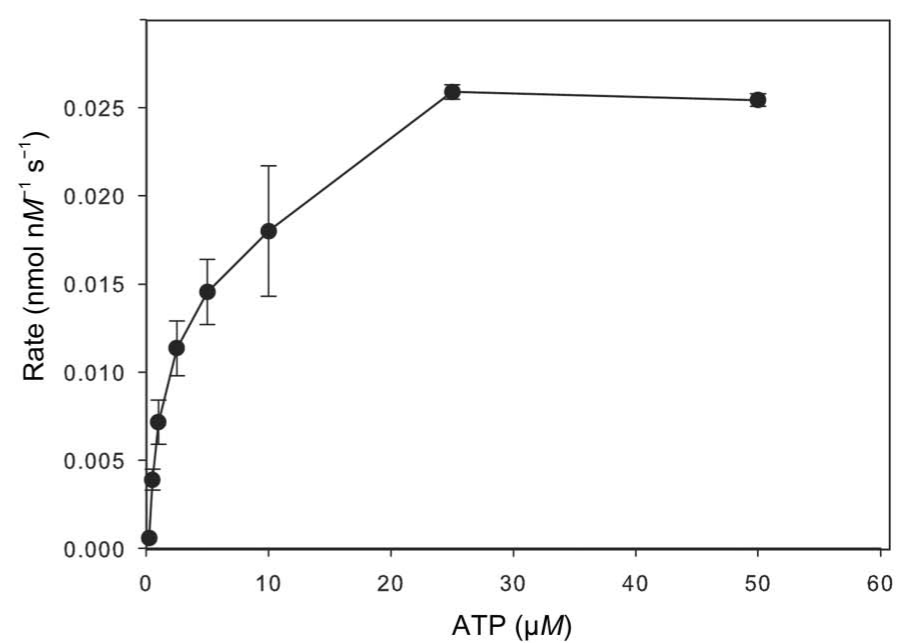

(b)

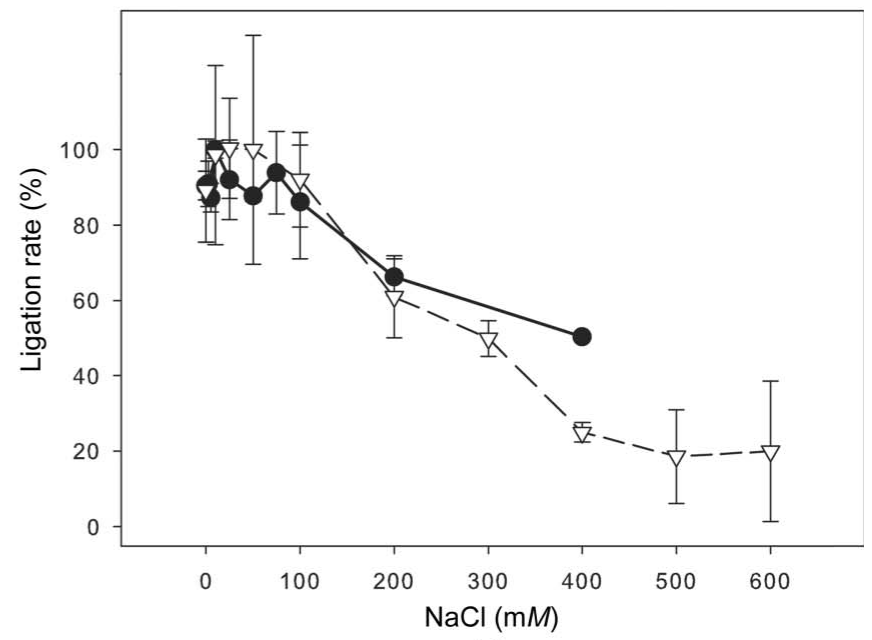

$(d)$

Figure 8

Kinetics of nick sealing by Psy-Lig and the effect of salt concentration measured using the MB assay. (a) The DNA (MB substrate) concentration was varied while the ATP concentration was kept at $0.1 \mu M$. (b) The ATP concentration was varied while the DNA concentration was kept at $300 \mathrm{n} M$. (c) Activity as a function of $\mathrm{MgCl}_{2}$ concentration. The inset shows the low-concentration data range for clarity. $(d)$ Activity as a function of NaCl concentration measured by the MB assay (solid line, circles) and the endpoint assay (dashed line, triangles). The measurements are the means of three replicate experiments; error bars represent the standard deviation from the mean. The values for the MB assay are the rates over the first 10 min of reaction, while the values for the endpoint assay are the ratio of ligated to unligated substrate. In $(c)$ and $(d)$ the data were normalized to the maximum rate under that condition and are expressed as a percentage. 
than in either T7-Lig or ChlV-Lig, as it is broken by a stretch of three prolines. In addition to a possible contribution from the large loop in the $\mathrm{OB}$ domain, the T7-Lig enzyme is proposed to bind DNA via a 31-residue loop in the AD domain which is protease-sensitive and has no electron density for nine residues in the crystal structure (Shuman, 2009). The equivalent region in Psy-Lig is the $\alpha 3-\alpha 4$ stretch, which forms half of the putative DNA-binding groove but is only seven residues long and has no possibility of circling the DNA.

\subsection{DNA ligase activity of Psy-Lig compared with other ligases}

Like the other minimal-type bacterial ADLs Nme-Lig, Hin-Lig and Vib-Lig (Cheng \& Shuman, 1997; Magnet \& Blanchard, 2004; Williamson \& Pedersen, 2014), Psy-Lig is able to efficiently ligate singly nicked DNA when the $5^{\prime}$-end is phosphorylated. This is in contrast to the larger ADLs from B. subtilis, Agrobacterium tumefaciens and M. tuberculosis, which have poor intrinsic nick-sealing activity in the absence of the Ku partner (Weller et al., 2002; Gong et al., 2004; Zhu \& Shuman, 2007; de Vega, 2013), although this is considerably stimulated by the presence of a single monoribonucleotide at the 3'-position of the nick (Zhu \& Shuman, 2008). Nme-Lig was also able to ligate cohesive ends after extended incubation; however, no activity was observed with gapped or bluntended substrates (Magnet \& Blanchard, 2004), while the sealing of a gapped substrate by Hin-Lig was less than 5\% of its nick-sealing activity (Cheng \& Shuman, 1997). The ability of Psy-Lig to act on the blunt substrate was somewhat surprising in light of the inactivity of Nme-Lig; however, it is possible that the activity of the latter was reduced by the retention of the N-terminal signal sequence in the recombinant construct tested. Comparison of the Vib-Lig homologue showed that nick sealing was increased more than twofold when the $\mathrm{N}$-terminal leader sequence was removed, and it is plausible that similar truncations of Hin-Lig and Nme-Lig would stimulate their activities further. Additionally, as the temperature was not specified, it is assumed that Nme-Lig was assayed at ambient temperature. Experiments with T4 DNA ligase have shown that cohesive and blunt-ended ligation is more efficient at lower temperatures (Ferretti \& Sgaramella, 1981), and this is likely to also be the case for bacterial ADLs.

The enzyme kinetics of Psy-Lig are similar to those of other small ADLs from diverse species; the affinity of Psy-Lig for DNA $\left(K_{\mathrm{m}}=124 \mathrm{n} M\right)$ is lower than that of either Nme-Lig $\left(K_{\mathrm{m}}=30 \mathrm{n} M\right.$; Magnet $\&$ Blanchard, 2004) or T4 DNA ligase $\left(K_{\mathrm{m}}=1.5 \mathrm{n} M\right.$; Hall \& Lehman, 1969); however, its catalytic efficiency $\left(k_{\mathrm{cat}} / K_{\mathrm{m}}=3.85 \times 10^{-4}\right)$ is equivalent to that of NmeLig $\left(k_{\text {cat }} / K_{\mathrm{m}}=2.83 \times 10^{4}\right)$ owing to the latter's relatively slow turnover number of $0.0085 \mathrm{~s}^{-1}$. The $K_{\mathrm{m}}$ for ATP, $3.8 \mu M$, is similar to those of other minimal bacterial ADLs and T4 DNA ligase (Hin-Lig, $0.2 \mu M$; Nme-Lig, $0.4 \mu M$; T4 DNA ligase, $0.6 \mu M$; Cheng \& Shuman, 1997; Magnet \& Blanchard, 2004; Hall \& Lehman, 1969) and lower than those of eukaryotes and eukaryotic viruses (mammalian ligase II, $40 \mu M$; ChlV-Ligm $75 \mu M$; Vaccinia virus DNA ligase, $95 \mu M$; Teraoka et al., 1986;
Ho et al., 1997; Shuman, 1995) or the larger bacterial ADL LigB from M. tuberculosis (340 $\mu$ M; Gong et al., 2004).

As with other DNA ligases, Psy-Lig absolutely requires $\mathrm{MgCl}_{2}$ for ligation activity. $\mathrm{Mg}^{2+}$ is the preferred metal for all ligases studied to date, but $\mathrm{Mn}^{2+}$ can also support some activity for Nme-Lig and Hin-Lig, as can $\mathrm{Ni}^{2+}, \mathrm{Ca}^{2+}$ and $\mathrm{Co}^{2+}$ to a much lesser extent (Cheng \& Shuman, 1997; Magnet \& Blanchard, 2004). The sensitivity of Psy-Lig to $\mathrm{NaCl}$ concentration was somewhat surprising, given that the predicted periplasmic location of this enzyme in a marine bacterium would expose it to $\mathrm{NaCl}$ concentrations of up to $600 \mathrm{mM}$. $\mathrm{NaCl}$ sensitivity of ligase activity has been reported for a number of ADLs; for example, the enzyme from Methanocaldococcus jannaschii shows a significant decrease above $50 \mathrm{~m} M$ (Wang et al., 2013), while for T4 DNA ligase the affinity for DNA is affected, with the $K_{\mathrm{m}}$ increasing fourfold in the presence of $200 \mathrm{nM} \mathrm{NaCl}$ (Cherepanov \& de Vries, 2003).

\subsection{Sequence homology with other putative periplasmic ligases}

Many of the minimal ADLs from gammaproteobacteria have strong predictions of cleavable leader sequences that direct them to the periplasmic space. Previous suggestions for the biological role of such periplasmically localized DNA ligases include the protection and repair of exogenous DNA prior to uptake during transformation (Magnet \& Blanchard, 2004), and although the localization of these enzymes has yet to be directly verified, many bacterial species possessing this type of ADL have been demonstrated to be naturally competent (Johnston et al., 2014).

Psy-Lig has high sequence homology with other previously characterized minimal bacterial ADLs: Nme-Lig (43\% identity, $71 \%$ similarity), Hin-Lig ( $41 \%$ identity, $76 \%$ similarity) and Vib-Lig (44\% identity, $75 \%$ similarity). All four sequences are remarkably similar in length, with the greatest variation being in the $\mathrm{N}$-terminal 30 amino acids where the periplasmic leader sequence is predicted. In addition to the conserved motifs found in all nucleotidyltransferase enzymes (I, III, IIIa, IV, V and VI marked in Fig. 2b), areas of sequence similarity are found for most of the putative DNA-interaction sites identified in the Psy-Lig structure. The $\beta 9-\beta 10$ loop which occupies an equivalent position to the ChlV-Lig latch has a fully conserved GKG motif followed by a positive (Lys or Arg) or polar (Gln) residue and then in the case of Psy-Lig, Vib-Lig and Hin-Lig an aromatic side chain (Tyr or Phe) and the glutamate. Gly199 and Ala200 which contribute to the partial positive surface of the Psy-Lig OB domain through their backbone amides are also fully conserved, as are most of the residues from the beginning of $\beta 11$ to the beginning of $\alpha 7$ which line the concave OB-domain surface. All three homologues have two or three prolines immediately after $\alpha 7$, suggesting that, as in Psy-Lig, this helix is truncated compared with the ChlV-Lig and T7-Lig structures. Conserved regions are also seen in the $\mathrm{AD}$ domain. In particular, the $\beta 3-\alpha 2$ loop includes a number of conserved or homologous residues and all three have bulky charged side chains at the end of $\alpha 3$. 
The sequence-based alignment of Psy-Lig with the three other biochemically characterized minimal bacterial ADLs (Fig. 2b) indicates that all four homologues lack large loop regions but the majority of the putative DNA-binding residues identified in Psy-Lig are conserved. This suggests that a similar mode of DNA binding may be common to these minimal bacterial ADLs. The Vib-Lig enzyme, like Psy-Lig, was sourced from a psychrophilic marine bacterium, while Hin-Lig and Nme-Lig are from mesophilic human pathogens. Like Psy-Lig, all three homologues are competent in independent adenylation and nick-sealing activities without requiring additional interaction partners. That Psy-Lig has fewer unstructured regions and shorter loops compared with homologous structures from ChlV-Lig and T7-Lig was somewhat counterintuitive given the psychotolerant origin of Psy-Lig. However, the sequence similarity of Psy-Lig to the mesophilic Hin-Lig and Nme-Lig suggests that this cannot be attributed to psychrophilicity, but rather some common feature of this type of bacterial ATP-dependent DNA ligase. The absence of flexible loops would be consistent as an adaptation to their predicted periplasmic location as the bacterial periplasam contains a large number of proteases (Merdanovic et al., 2011). Prior to structural determination, the latch region of ChlV-Lig and the AD and OB loops of T7Lig had already been delineated as potential sites of dynamic interaction based on their protease sensitivity (Odell \& Shuman, 1999; Subramanya et al., 1996), therefore for a periplasmically located ligase there would be a strong selective pressure towards structures which do not require labile regions that are susceptible to degradation.

\section{Conclusions}

In summary, we have conducted a detailed structural and biochemical study of Psy-Lig, a previously uncharacterized ATP-dependent DNA ligase. The absence of extensive loops or disordered regions in the high-resolution crystal structure of the enzyme-adenylate suggests that Psy-Lig binds to DNA with incomplete encirclement of the duplex using only the ridged, positively charged surfaces on its two domains. Extensive enzyme assays revealed that Psy-Lig has intrinsic ATP-dependent ligase activity for variety of double-stranded DNA substrates and has similar kinetic constants to other small ADLs from viruses and bacteria. Sequence homology with other putatively periplasmic, minimal-type bacterial ADLs suggests that the lack of loop regions could be an adaptation to the protease-rich environment in which these enzymes are expected to function.

We would like to thank the Troms $\varnothing$ University Proteomics Platform (TUPP) for technical assistance in protein identification by mass spectrometry. Provision of beam time on BL14.1 at BESSY II, Berlin, Germany is gratefully acknowledged. This work was supported by the Research Council of Norway (Grant No. 192123); The Norwegian Structural Biology Centre (NorStruct) is supported by the National
Functional Genomics Program (FUGE) of the Research Council of Norway.

\section{References}

Afonine, P. V., Grosse-Kunstleve, R. W., Echols, N., Headd, J. J., Moriarty, N. W., Mustyakimov, M., Terwilliger, T. C., Urzhumtsev, A., Zwart, P. H. \& Adams, P. D. (2012). Acta Cryst. D68, 352-367. Akey, D., Martins, A., Aniukwu, J., Glickman, M. S., Shuman, S. \& Berger, J. M. (2006). J. Biol. Chem. 281, 13412-13423.

Cheng, C. \& Shuman, S. (1997). Nucleic Acids Res. 25, 1369-1374.

Cherepanov, A. V. \& de Vries, S. (2003). Eur. J. Biochem. 270, 43154325.

Cotner-Gohara, E., Kim, I.-K., Hammel, M., Tainer, J. A., Tomkinson, A. E. \& Ellenberger, T. (2010). Biochemistry, 49, 6165-6176.

Delcher, A. L., Bratke, K. A., Powers, E. C. \& Salzberg, S. L. (2007). Bioinformatics, 23, 673-679.

Della, M., Palmbos, P. L., Tseng, H.-M., Tonkin, L. M., Daley, J. M., Topper, L. M., Pitcher, R. S., Tomkinson, A. E., Wilson, T. E. \& Doherty, A. J. (2004). Science, 306, 683-685.

Doherty, A. J. \& Suh, S. W. (2000). Nucleic Acids Res. 28, 40514058.

Dolinsky, T. J., Czodrowski, P., Li, H., Nielsen, J. E., Jensen, J. H., Klebe, G. \& Baker, N. A. (2007). Nucleic Acids Res. 35, W522W525.

Emsley, P. \& Cowtan, K. (2004). Acta Cryst. D60, 2126-2132.

Ferretti, L. \& Sgaramella, V. (1981). Nucleic Acids Res. 9, 85-93.

Gong, C., Martins, A., Bongiorno, P., Glickman, M. \& Shuman, S. (2004). J. Biol. Chem. 279, 20594-20606.

Hall, Z. W. \& Lehman, I. R. (1969). J. Biol. Chem. 244, 43-47.

Ho, C. K., Van Etten, J. L. \& Shuman, S. (1997). J. Virol. 71, 19311937.

Johnston, C., Martin, B., Fichant, G., Polard, P. \& Claverys, J. P. (2014). Nature Rev. Microbiol. 12, 181-196.

Kiyonari, S., Takayama, K., Nishida, H. \& Ishino, Y. (2006). J. Biol. Chem. 281, 28023-28032.

Lakshmipathy, U. \& Campbell, C. (1999). Mol. Cell. Biol. 19, 38693876.

Langer, G., Cohen, S. X., Lamzin, V. S. \& Perrakis, A. (2008). Nature Protoc. 3, 1171-1179.

Liu, S., Liu, X., Kamdar, R. P., Wanotayan, R., Sharma, M. K., Adachi, N. \& Matsumoto, Y. (2013). Biochem. Biophys. Res. Commun. 439, 173-178.

Magnet, S. \& Blanchard, J. S. (2004). Biochemistry, 43, 710-717.

Martin, I. V. \& MacNeill, S. A. (2002). Genome Biol. 3, reviews3005.

Merdanovic, M., Clausen, T., Kaiser, M., Huber, R. \& Ehrmann, M. (2011). Annu. Rev. Microbiol. 65, 149-168.

Nair, P. A., Nandakumar, J., Smith, P., Odell, M., Lima, C. D. \& Shuman, S. (2007). Nature Struct. Mol. Biol. 14, 770-778.

Nishida, H., Tsuchiya, D., Ishino, Y. \& Morikawa, K. (2005). Acta Cryst. F61, 1100-1102.

Odell, M. \& Shuman, S. (1999). J. Biol. Chem. 274, 14032-14039.

Odell, M., Sriskanda, V., Shuman, S. \& Nikolov, D. B. (2000). Mol. Cell, 6, 1183-1193.

Pascal, J. M., O'Brien, P. J., Tomkinson, A. E. \& Ellenberger, T. (2004). Nature (London), 432, 473-478.

Pascal, J. M., Tsodikov, O. V., Hura, G. L., Song, W., Cotner, E. A., Classen, S., Tomkinson, A. E., Tainer, J. A. \& Ellenberger, T. (2006). Mol. Cell, 24, 279-291.

Petersen, T. N., Brunak, S., von Heijne, G. \& Nielsen, H. (2011). Nature Methods, 8, 785-786.

Pitcher, R. S., Brissett, N. C. \& Doherty, A. J. (2007). Annu. Rev. Microbiol. 61, 259-282.

Schneider, C. A., Rasband, W. S. \& Eliceiri, K. W. (2012). Nature Methods, 9, 671-675.

Sheldrick, G. M. (2010). Acta Cryst. D66, 479-485.

Shuman, S. (1995). Biochemistry, 34, 16138-16147.

Shuman, S. (2009). J. Biol. Chem. 284, 17365-17369. 
Shuman, S. \& Lima, C. D. (2004). Curr. Opin. Struct. Biol. 14, 757-764.

Sriskanda, V. \& Shuman, S. (2002). J. Biol. Chem. 277, 9695-9700.

Subramanya, H. S., Doherty, A. J., Ashford, S. R. \& Wigley, D. B. (1996). Cell, 85, 607-615.

Tang, Z., Wang, K., Tan, W., Li, J., Liu, L., Guo, Q., Meng, X., Ma, C. \& Huang, S. (2003). Nucleic Acids Res. 31, e148.

Teraoka, H., Sumikawa, T. \& Tsukada, K. (1986). J. Biol. Chem. 261, 6888-6892.

Tomkinson, A. E., Vijayakumar, S., Pascal, J. M. \& Ellenberger, T. (2006). Chem. Rev. 106, 687-699.

Vega, M. de (2013). PLoS One, 8, e64232.

Wang, Y., Xie, J.-J., Han, Z., Liu, J.-H. \& Liu, X.-P. (2013). Protein Expr. Purif. 87, 79-86.

Weller, G. R., Kysela, B., Roy, R., Tonkin, L. M., Scanlan, E., Della, M., Devine, S. K., Day, J. P., Wilkinson, A., d'Adda di Fagagna, F., Devine, K. M., Bowater, R. P., Jeggo, P. A., Jackson, S. P. \& Doherty, A. J. (2002). Science, 297, 1686-1689.
Wilkinson, A., Day, J. \& Bowater, R. (2001). Mol. Microbiol. 40, 1241-1248.

Williamson, A. \& Pedersen, H. (2014). Protein Expr. Purif. 97, 29-36.

Wright, D., DeBeaux, A., Shi, R., Doherty, A. J. \& Harrison, L. (2010). Mutagenesis, 25, 473-481.

Zhu, H., Bhattarai, H., Yan, H.-G., Shuman, S. \& Glickman, M. S. (2012). Biochemistry, 51, 10147-10158.

Zhu, H., Nandakumar, J., Aniukwu, J., Wang, L. K., Glickman, M. S., Lima, C. D. \& Shuman, S. (2006). Proc. Natl Acad. Sci. USA, 103, 1711-1716.

Zhu, H. \& Shuman, S. (2005). J. Biol. Chem. 280, 418-427.

Zhu, H. \& Shuman, S. (2006). J. Biol. Chem. 281, 13873-13881.

Zhu, H. \& Shuman, S. (2007). Nucleic Acids Res. 35, 36313645.

Zhu, H. \& Shuman, S. (2008). J. Biol. Chem. 283, 8331-8339.

Zhu, H., Wang, L. K. \& Shuman, S. (2005). J. Biol. Chem. 280, 3370733715. 